\title{
Management of Vortices Trailing Flapped Wings via Separation Control
}

\author{
David Greenblatt ${ }^{*}$ \\ Flow Physics and Control Branch, NASA Langley Research Center, Hampton VA 23681-2199
}

\begin{abstract}
A pilot study was conducted on a flapped semi-span model to investigate the concept and viability of near-wake vortex management via separation control. Passive control was achieved by means of a simple fairing and active control was achieved via zero mass-flux blowing slots. Vortex sheet strength, estimated by integrating surface pressure ports, was used to predict vortex characteristics by means of inviscid rollup relations. Furthermore, vortices trailing the flaps were mapped using a seven-hole probe. Separation control was found to have a marked effect on vortex location, strength, tangential velocity, axial velocity and size over a wide range of angles of attack and control conditions. In general, the vortex trends were well predicted by the inviscid rollup relations. Manipulation of the separated flow near the flap edges exerted significant control over both outboard and inboard edge vortices while producing negligible lift excursions. Dynamic separation and attachment control was found to be an effective means for dynamically perturbing the vortex from arbitrarily long wavelengths down to wavelengths less than a typical wingspan. In summary, separation control has the potential for application to time-independent or time-dependent wake alleviation schemes, where the latter can be deployed to minimize adverse effects on ride-quality and dynamic structural loading.
\end{abstract}

\section{Nomenclature}

$\begin{array}{ll}A & =\text { wing area, } s \times c \\ A R & =\text { wing aspect ratio } \\ c & =\text { wing chord-length } \\ h & =\text { slot width } \\ \Delta H & =\text { viscous head-drop } \\ C_{l} & =\text { sectional lift coefficient } \\ C_{L} & =\text { wing lift coefficient } \\ C_{m} & =\text { sectional moment coefficient } \\ C_{M} & =\text { wing moment coefficient } \\ C_{P} & =\text { time mean pressure coefficient } \\ C_{\mu} & =\text { slot momentum coefficient, } h / c\left(u_{j} / U_{\infty}\right)^{2} \\ f_{e} & =\text { separation control excitation frequency } \\ f_{w} & =\text { wake control frequency } \\ F^{+} & =\text {reduced excitation frequency, } f_{e} L_{f} / U_{\infty} \\ k & =\text { dimensionless wake frequency, } f_{w} L_{f} / U_{\infty} \\ L_{f} & =\text { flap length, from slot to trailing-edge } \\ q & =\text { free-stream dynamic pressure } \\ R e & =\text { Reynolds number based on chord-length } \\ u_{j} & =\text { peak slot velocity } \\ U_{\infty} & =\text { free-stream velocity } \\ U, V, W & =\text { mean velocities in directions } x, y, z \\ V_{x}, V_{r}, V_{\theta} & =\text { mean wake velocities in directions } x, r, \theta \\ r_{1} & =\text { vortex location corresponding to } V_{\theta, \text { max }} \\ & \end{array}$

\footnotetext{
${ }^{*}$ NRC Research Associate, Flow Physics \& Control Branch, Mail Stop 170, Senior Member.
} 


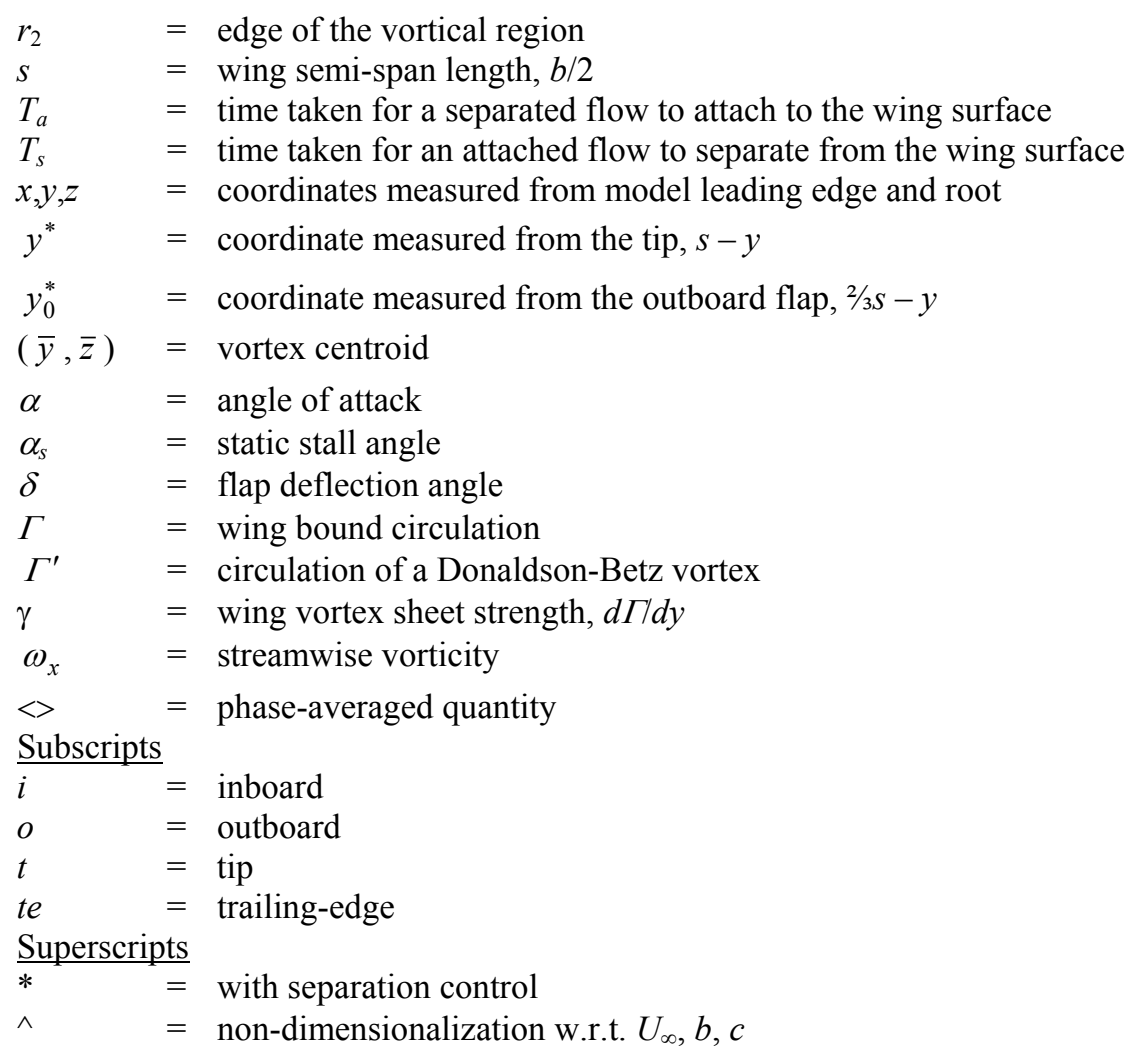

\section{Introduction}

\section{A. Background}

The hazard posed by powerful vortices trailing large commercial airliners has long been the subject of extensive research. ${ }^{1,2,3}$ Aircraft that encounter or penetrate these vortices can experience severe upward or downward loads as well as overpowering rolling moments, depending on their size as well as their location and orientation with respect to the vortices. This hazard is most severe near airports where planes fly in close proximity and where the relatively low flight speeds result in enhanced vortex strength. Although the vortices are usually transported away by selfinduction or by atmospheric currents, this is not always the case and several accidents have been attributed to vortex encounters in recent decades. ${ }^{4}$ Under present visual and instrument flight rules, the delays due to separation distances are often larger than those dictated by other factors, and thus add to airport delays and congestion. ${ }^{5}$

There has long been an urgent need to destroy vortices or cause them to dissipate to some acceptable level. Methods employing "turbulence injection," by means of spoilers, splines, vortex generators, and fins generally produce insufficient far-field alleviation and often significantly increase drag. ${ }^{6,7}$ An alternative approach is to somehow exploit unstable vortex growth such that they ultimately interact, pinch-off, and degenerate into harmless small-scale turbulence. The origin of this concept is based on wake instability observations ${ }^{8}$ that were subsequently analyzed and explained in terms of mutual induction. ${ }^{9}$ Two main approaches are proffered: time-invariant methods and time-dependent methods. (These are also referred to as passive and active methods, but the present terminology is adopted to avoid confusion with boundary layer separation control methods discussed below.) Time-invariant methods rely on modifying the span loading to establish two or more pairs of opposite-signed counter-rotating vortices and allow naturally arising instabilities to bring about linking and mutual destruction of the vortices. Some examples include appropriately configuring inboard flap vortices, ${ }^{10}$ employing multiple differentially deflected flaps $^{11,12}$ or employing triangular outboard flaps. ${ }^{13}$ Time-dependent methods that actively force the breakup of vortices are realized, for example, by differentially deflecting inboard and outboard control surfaces ("sloshing" of the lift distribution ${ }^{14,15}$ ). This method was tested in a towing tank, ${ }^{16}$ where measured amplification rates agreed qualitatively with theoretical predictions. Recently, a similar approach was perused with a view to exploiting the multiple vortex growth mechanisms created by an airplane on approach with flaps down. Numerical simulations and towing tank experiments showed a breakup of the trailing vortices more rapidly than a comparable excitation of the Crow instability on a single pair of vortices. Despite their inherent appeal, active methods must address issues such 
as "ride quality, dynamic-load effects on the structure, and the ability to maintain control authority during operation". ${ }^{17}$

\section{B. Flap Vortices}

"Flaps-down" is a pseudonym for complex "high-lift systems" deployed by all large airlines to achieve the low speeds required for take-off and landing. ${ }^{18,19}$ Vortices shed from the flap edges are not only significant; they apparently dominate the ensuing wake structure. For example, at typical approach angles of attack $(\sim 5 \mathrm{deg}){ }^{18}$ the flap vortex strength exceeds the strength of the wing-tip vortices and the two vortices usually merge at a number of span-lengths downstream. ${ }^{20}$ In configurations with both inboard and outboard flaps, universal amongst large airliners, the outboard flap vortex dominates the vortex field ${ }^{21}$ while the inboard vortex apparently remains significant yet separate from the outboard-wing tip combination for a considerable distance downstream. A stability analysis of such a two-vortex pair, ${ }^{22}$ revealed short wavelength instabilities with growth-rates up to 2 times larger than the Crow instability. The unstable wavelengths depend on vortex-core size, spacing and strength. In addition, a transient growth mechanism was identified that can amplify an initial disturbance by a factor of 10 to 15 in one-fifth of the time required for the same growth due to instability at the same wavelength. It is evident, therefore, that the characteristics of the flap-edge vortices must play an important role in any successful wake vortex alleviation strategy.

\section{Boundary Layer Separation Control}

While high-lift systems are effective in delivering the required $C_{L}$, they are aerodynamically inefficient due to flow separation on flaps and in the wing-flap cove region, ${ }^{23}$ particularly during landing. Although separated flow is generally associated with aerodynamic inefficiency, it may also be viewed as a resource that is a by-product of the high-lift system. This resource can be harnessed by enhancing flow attachment to the surfaces, for example by means of passive devices ${ }^{24}$ or low-energy active perturbations. ${ }^{25}$ The control of separation directly affects lift, or bound circulation $\Gamma$, and therefore has the potential to modify the vortex sheet strength (or shed vorticity) $\gamma=d \Gamma / d y$. Since the vortex sheet on a flapped wing rolls up into multiple distinct vortices, boundary layer separation control emerges as a strong candidate for directly controlling, or managing, the individual vortices. Moreover, local control of separation, e.g. over some fraction of the flap span, has the potential for locally modifying $\gamma$, thereby exerting control over individual vortices while simultaneously minimizing lift excursions. However, there is presently no data available for active separation control in the highly three-dimensional flap-edge region.

Active separation control methods, in general, provide greater flexibility in that they have greater authority and can control the degree of boundary layer separation. Furthermore, separation and attachment can be controlled dynamically. ${ }^{26}$ Therefore, if separation control can be shown to be a feasible means of managing trailing vortices, then dynamic separation and attachment can be further exploited to achieve this in a time-dependent manner. Dynamic separation control can then be employed for directly exciting wake instabilities.

\section{Objective \& Scope}

The concept and viability of vortex management via separation control was investigated by conducting a pilot study involving a semi-span model wing. The wing was installed and tested in the Basic Aerodynamics Research Tunnel (BART) at the NASA Langley Research Center. Details of the wing design and setup are provided in section II. The wing is equipped with three flaps, each with its own excitation slot that was configured to produce zero net mass-flux excitation. Span loading was estimated using surface pressure ports and dynamic response of the flow was ascertained by means of unsteady pressure ports. Empirical span-loading data were used together with inviscid vortex rollup relations (section III.A; IV) to predict the near-field vortex characteristics such as location, strength, peak velocities, and vortex size. Flow field measurements using a seven-hole probe were performed in the nearwake of the wing and the vortex characteristics were compared to the inviscid rollup predictions (section III.A; IV).

This pilot study presently does not address the intermediate of far-field vortex structure. The primary objective is to assess the use of separation control for generating boundary conditions that are consistent with those believed to effective for time invariant and time dependent vortex alleviation strategies.

\section{Experimental Setup}

\section{A. Semi-Span Model}

Experiments were performed on a rectangular planform semi-span NACA 0015 port-side model wing of aspect ratio $A R=4$ (semi-span $s=609.6 \mathrm{~mm}$, chord $c=304.8 \mathrm{~mm}$ ) cantilevered off the wall of a low-speed wind tunnel (see 
figs. 1a-1c). The model has a main element and three simple flaps (inboard, outboard, and tip) of equal span $\left(s_{f}\right.$ $=s / 3$ ), with the hingeline at the $70 \%$ chord (see fig. 2a). Each flap is independently adjustable through a range of $10^{\circ}$ (upwards) to $40^{\circ}$ (downwards) with indexed settings in $10^{\circ}$ increments. The coordinate system used in this paper is defined in the figure. Fig. $1 \mathrm{~b}$ shows the inboard and outboard flaps deflected: $\left(\delta_{i}, \delta_{o}, \delta_{t}\right)=\left(20^{\circ}, 20^{\circ}, 0^{\circ}\right)$ and fig. $1 \mathrm{c}$ shows only the outboard flap deflected: $\left(\delta_{i}, \delta_{o}, \delta_{t}\right)=\left(0^{\circ}, 20^{\circ}, 0^{\circ}\right)$. Flap angles are maintained using brackets between the main element and flaps that are flush with the airfoil surface. The model has a blowing slot at the shoulder of each flap, each with a width of $0.76 \mathrm{~mm}$. (The main element has an additional leading edge slot with a width of $0.5 \mathrm{~mm}$ that was not used in this study.) The model is constructed from aluminum, apart from the slot edges that are constructed from stainless steel in order to maintain a $0.25 \mathrm{~mm}$ edge. The wing tip plate is square and set to be flush with the edge of the tip flap. The tip is removable and can be replaced with different arbitrarily-shaped tips.

\section{B. Types of Control}

The main element is effectively hollow, apart from necessary internal structure, and acts as a plenum for the various slots on the wing surface. It incorporates a main spar that includes three removable internal, sealed partitions and an upper cover plate. Fig. $2 \mathrm{~b}$ shows the partition locations with different options for the partition installation. Thus, when the main element is assembled, one of the three internal partitions can be installed within the plenum, forming sealed sub-plenums that are sealed using o-rings. Zero mass-flux perturbations are introduced via two voice-coil type actuators that are connected to the sub-plenums via manifolds (J. Kiedaisch, H. Nagib \& Associates, IIT). The resulting sub-plenums are in fluidic communication with an adjacent flap-shoulder slot which produces the perturbations (fig. 2c). In addition to the active flow control setup described above, passive control was exerted by placing a fairing over the slot between the main element and flap upper surface (fig. $2 \mathrm{~d}$ ). This eliminated the small backward facing step introduced by the slot, thereby forming a smooth transition between the main element and flap.

\section{Measurement Techniques}

The model is further equipped with 165 static pressure ports arranged in a perpendicular spanwise and chordwise grid. The spanwise ports are located at the chordwise locations $x / c=5 / 100,3 / 10,77 / 100$, and 1 , and are grouped more closely near the tip. The chordwise ports are located at spanwise locations $y / s=1 / 6,1 / 25 / 6$ and 99/100, and are grouped more closely near the leading-edge, while the flaps are equipped with additional ports. Surface pressures were integrated in order to compute aerodynamic coefficients and estimates of pressures within the grid were obtained using a three-dimensional interpolation method (see Appendix A). The model is also equipped with nine dynamic pressure transducers on the wing upper surface. Slot velocities were calibrated using a hot-wire anemometer and actuator performance was monitored using unsteady transducers mounted within the wing plenums.

Wing static pressures were measured using a high-speed pressure scanner and unsteady pressures were measured by means of piezoresistive unsteady pressure transducers. A $1.6 \mathrm{~mm}$ diameter seven-hole probe, with accuracy better than $1 \%$ on the velocity magnitude and 0.5 degrees on the flow angles, was used to make wake measurements at $x / c=2$.

\section{Data Reduction Methods}

\section{A. Inviscid Rollup Relations}

To predict the effect of separation control on vortices trailing the flaps, we employ the method of Betz, ${ }^{27}$ in the form developed and validated by Donaldson et al. ${ }^{28}$ The method is well documented, and thus only a brief description of the main assumptions, and present implementation, are presented here. Limitations of the method as well as the present implementation are discussed below. Betz's method does not explicitly treat the rollup mechanism, but rather employs three conservation relations between the span-loading $\Gamma(y)$ and the rolling-up vortex circulation $\Gamma^{\prime}(r)$. Betz employed the conservation of vorticity, and also postulated that the first and second moments of vorticity are conserved. Despite the relative simplicity of the method, Donaldson et al. ${ }^{28}$ showed that it predicts flap vortex details that are in surprisingly good agreement with aircraft-wake experimental data.

For complex wing-load distributions, such as those associated with flapped wings, Donaldson et al. ${ }^{28}$ showed that circulation becomes multi-valued during the rollup calculation and thus a single vortex rollup is not physically possible. Moreover, they appreciated that such wing-load distributions give rise to multiple vortices, at least in the near-field. Their first innovation was to assume that the vorticity shed between adjacent local $|d \Gamma / d y|$ minima rolls-up into individual vortices. Secondly, they assumed that the local shed vorticity peak between the adjacent 
minima $\left(|d \Gamma / d y|_{\max }\right)$, located at $y=y_{\max }$, progresses into the center of that specific vortex. These two innovations are in essence consistent with the original assumptions of $\mathrm{Betz}^{27}$ and validated theoretically by Yates. ${ }^{29}$

Using the Donaldson-Betz method, the vorticity between adjacent $|d \Gamma / d y|$ minima $y_{A}$ and $y_{B}$ rolls-up into a vortex located at the centroid $\bar{y}$. Consequently, the strength of a fully rolled-up vortex is simply:

$$
\Gamma^{\prime}\left(r_{2}\right)=\int_{y_{A}}^{y_{B}} \frac{d \Gamma}{d y} d y=\Gamma\left(y_{A}\right)-\Gamma\left(y_{B}\right),
$$

where the centroid is located at

$$
\bar{y}=\frac{1}{\Gamma^{\prime}\left(r_{2}\right)} \int_{y_{A}}^{y_{B}} y \frac{d \Gamma}{d y} d y
$$

To write an expression for the radius $\left(r_{2}\right)$ at which the circulation $\Gamma^{\prime}$ is equal to $\Gamma\left(y_{A}\right)-\Gamma\left(y_{B}\right)$, we assume that the $y_{B}-\bar{y} \approx \bar{y}-y_{A}$ and thus

$$
r_{2} \approx \frac{y_{B}-y_{A}}{2}
$$

This approximates the radius at which the tangential velocity blends with the point vortex field. ${ }^{2}$ Finally, using the equation for an inviscid vortex, and a relation similar to that of eqn. 3 , they derived a simple relation for the velocity at the center of the vortex:

$$
V_{\theta}(0)=-\frac{1}{\pi}\left(\frac{d \Gamma}{d y}\right)_{y=y_{\max }}
$$

The relations expressed in eqns. 1 to 4 provide four basic characteristics of the rolled up vortex. For the present implementation of the method, the span loading $\Gamma(y)$ is measured directly from the experiment. To obtain closed form expressions, we assume that the lift, or circulation, distribution in the intermediate vicinity of the flap interface is of the form:

$$
\Gamma(y)=a_{0}+a_{1} y+a_{2} y^{2}+a_{3} y^{3}
$$

and fit a least squares curve to the experimental data in the vicinity of the flap edge. The closed form expressions can be found in Appendix B.

Simplifying assumptions associated with the above method: e.g. two-dimensionality; inviscid flow; vortices considered in isolation of one another; non-conservation of kinetic energy; are well known. ${ }^{37,38}$ Moreover, the spanloading measurements are relatively course (18 spanwise locations). However, given the relative simplicity and rapidity of span-loading measurements versus wake-surveys, the method is of much usefulness for ascertaining trends. Moreover, in applying the method to flow control, the limitations become less important when we compare changes between baseline (uncontrolled) and controlled states, for example $\Delta \bar{y}=\bar{y}^{*}-\bar{y}, V_{\theta}^{*}(0) / V_{\theta}(0), \Gamma^{*} / \Gamma^{\prime}$, and $r_{2}^{*} / r_{2}$, where asterisks indicate control.

\section{B. Wake Measurements}

All wake measurements were performed in a plane at $x / c=2$, by means of a seven-hole probe, yielding $(U, V, W)$ as a function of $(y, z)$. Streamwise vorticity was calculated according to:

$$
\omega_{x}=\partial W / \partial y-\partial V / \partial z
$$

using central differences. Vortex strength in the wake and the vortex centroid were determined by means of the standard definitions:

$$
\Gamma_{w}=\int \omega_{x} d A
$$

and

$$
\left(\bar{y}_{w}, \bar{z}_{w}\right)=\frac{1}{\Gamma_{w}} \int(y, z) \omega_{x} d A
$$

The tangential velocity $\left(V_{\theta}\right)$ and radial coordinate $(r)$ were determined from the in-plane velocity components $(V, W)$ and $(y, z)$ coordinates relative to the vortex centroid respectively. This allowed direct determination of the peak tangential velocity and the corresponding radius $\left(r_{1}\right)$. 
A curious consequence of applying the Donaldson-Betz method to flap vortices is that it predicts a finite centerline peak velocity $V_{d}(0)$. Also, the inviscid nature of the method precludes direct estimation of $r_{1}$, which corresponds to $V_{\theta, \max }$ for a real vortex. Thus, for comparison purposes, peak velocities measured in the trailing vortex $\left(V_{\theta, \text { max }}^{*} / V_{\theta, \text { max }}\right)$ were compared with the Donaldson-Betz $V_{\theta}^{*}(0) / V_{\theta}(0)$. In addition, seven-hole probe data allowed far more precise measurement of $r_{1}$ than of $r_{2}$. Thus, for the purpose of comparing measured vortex core sizes $r_{1}^{*} / r_{1}$ with rollup predictions, it was assumed that $r_{2} / r_{1}$ is constant for any two Donaldson-Betz vortices.

\section{Discussion of Results}

\section{A. Symmetric Wing Characteristics}

Baseline $C_{L}$ versus $\alpha$ data at two Reynolds numbers, without flap deflections, are shown in fig. 3a and the wing span-loading is shown in fig. 3b. Data acquired at even angles are for $\alpha$ increasing and odd angles are for $\alpha$ decreasing. Differences between $R e=500,000$ and $R e=1,000,000$ are minor, for two reasons: firstly the leading edge slot effectively trips the boundary layer and, secondly, the sharp square wing tip fixes separation on the lower side of the wing independent of $R e$. The wing stalls inboard, as expected, around $\alpha=14^{\circ}$. The distortion of the load distribution near the tip of the wing $(y / s>0.97)$ is due to the formation of vortex (or vortices) at the wing tip. ${ }^{30}$ These measurements are consistent with data of other investigations ${ }^{30,31}$ at higher Reynolds numbers and aspect ratios (figs. $4 a-4 d)$. Note that the majority of the pressure data points shown in figs. $4 b$ and $4 d$ were obtained using the interpolation scheme described in Appendix A. It is thus evident that the flap slots do not have a noticeable effect on the details of the tip vortex rollup or span loading.

\section{B. Inboard \& Outboard Flap Deflection}

The first configuration considered here was the deflection of both inboard and outboard flaps $\left(\delta_{i}, \delta_{o}, \delta_{t}\right)=\left(20^{\circ}, 20^{\circ}, 0^{\circ}\right)$ as shown in fig. 1b. This is equivalent to the deflection of a single inboard flap of span of $2 / 3 S$ because the flaps are directly adjacent to one another. Zero mass-flux excitation was introduced along the entire length of the slot. Lift coefficient data presented in fig. $5 \mathrm{a}$ and $5 \mathrm{~b}$ are for the baseline case as well as control applied at two amplitudes, at an inboard location $(y / s=1 / 6)$ and the overall wing respectively. As expected, inboard control (fig. 5a), where three-dimensional effects are small, is similar to that observed on two-dimensional wings. At relatively low amplitude $\left(C_{\mu}=0.21 \%\right)$, control is effective at $\alpha<0^{\circ}$ but its effectiveness gradually diminishes as $\alpha$ approaches $\alpha_{s}=12^{\circ}$. This can be further appreciated from the wing pressure distributions at $\alpha=-4^{\circ}$ (fig. 6a) and $8^{\circ}$ (fig. 6b). The overall effect of separation control on $C_{L}$ at both amplitudes is qualitatively similar to the inboard $C_{l}$ results, but the differences between baseline and control are smaller. This is because separation control is only effective over the flap, while lift over the remainder of the wing towards the tip is not significantly affected (fig. 6c). Nevertheless, it should be noted that separation control retains its effectiveness across the entire span of the flap. This is evident from the change in $C_{l}$ (fig. 6c) that remains approximately constant at 0.25 across the span of wing corresponding to the deflected flap. Furthermore, the trailing-edge pressure recovery, as exemplified by $C_{P, t e}$, shows a nearly uniform change across the span of the flap when control is imposed. The flap vortex begins rolling up at the flap edge in much the same way as the tip vortex does (figs. $3 b$ and $4 a$ ), as is evident from the relatively low pressure at the edge of the flap trailing-edge (fig. 6c). This is true for both baseline and control scenarios.

The experimentally determined span-loading (e.g. fig. 6c) was used as input to the rollup relations (eqns. 1-4), to predict the effect of separation control on the four basic characteristics of the flap vortex (see figs. 7a-7d). The data are shown in dimensionless form as a function of $\alpha$ for the baseline and two control cases are considered in figs. 5 and 6. As a general rule, the predictions indicate that separation control strengthens the vortex (fig. 7a), moves the centroid outboard (fig. 7b), increases the peak velocity (fig 7c) and reduces the vortex size (fig. 7d). The extent to which vortex strength and peak velocity are controlled depends to some extent on the degree of separation control. At low $\alpha$ significant authority is achieved, but control over vortex strength and peak velocity diminishes as the wing stall angle $\left(\alpha_{s}=12^{\circ}\right)$ is approached. Nevertheless, significant authority is exerted over the centroid location and vortex size for a wide range of $\alpha$ up to stall. This true for both low and high amplitude control, even when the effect on wing lift is small. 
Table 1a. Comparison of inviscid rollup relation predictions with near-wake measurements for full flap control.

\begin{tabular}{|l|c|c|}
\hline & \multicolumn{2}{|c|}{ Full Flap Control } \\
\hline & 7-hole Probe & Donaldson-Betz \\
\hline$\Delta \bar{y} / s(\%)$ & 2.5 & 1.5 \\
\hline$\Gamma^{\prime *} / \Gamma^{\prime}$ & 1.31 & 1.65 \\
\hline$V_{\theta}^{*}(0) / V_{\theta}(0)$ & 1.29 & 1.33 \\
\hline$r_{2}^{*} / r_{2}$ & 0.68 & 0.81 \\
\hline
\end{tabular}

Direct measurements of the flap vortex at $\alpha=8^{\circ}$ downstream of the wing at $x / c=2$ are shown for the baseline case (fig. 8a) and the high amplitude control case (fig. 8b). Measurements were made at this location in an attempt to minimize interference from the tip vortex and tunnel walls. Table 1a shows a comparison of the measured vortex characteristics with those calculated from the rollup relations. The rollup relations predict the correct trends but only the peak velocity ratio is predicted accurately. The inaccuracies are most likely due to the limiting assumptions inherent in the Donaldson-Betz approach (see section IIIA) as well as the relatively sparse spanwise pressure measurement locations on the wing. The vortices are also observed to be not fully rolled up and axi-symmetric at $x / c=2$, but this is assumed to be a relatively small source of error when comparing differences or ratios.

Separation control also brings about significant changes to the vortex axial velocity, on the order of $0.3 U_{\infty}$. This can be explained qualitatively using Batchelor' ${ }^{32}$ analysis applied here to the flap vortex by considering a streamline which extends from upstream of the wing through the vortex centerline (also see ref. 33). The axial velocity on the centerline can then be written as:

$$
\frac{V_{x}(0)}{U_{\infty}}=\sqrt{1+\frac{\left[p_{\infty}-p(0)\right]-\rho g \Delta H}{\rho U_{\infty}^{2} / 2}}
$$

where the fist term in the quotient on the rhs is the pressure drop in the vortex $\left[\propto\left(\Gamma / r_{1}\right)^{2}\right]^{33}$ and the second term is a head-drop representing viscous losses. Considering the increased circulation and decreased size associated with the controlled vortex (figs. 8a, 8b and table 1a), it is clear from eqn. 9 that separation control acts to increase the vortex centerline axial velocity. In addition, note that the viscous losses in an attached boundary layer will be significantly less than those in a thicker separated shear layer. Thus control acts to further increase the centerline velocity by reducing the viscous head-drop. It is therefore a combination of increased pressure drop and decreased head-drop that are jointly responsible for the higher axial velocities.

Control of an initially separated flow affects the aerodynamic coefficient in different ways, depending on the angle of attack (or flap deflection). At low angles of attack, the flow is seen to fully attach when some threshold perturbation level $\left(C_{\mu}\right)$ is exceeded. At higher angles of attack, a coefficient such as $C_{L}$ varies gradually, approximately logarithmically with $C_{\mu}$. These effects are illustrated with respect to relatively low and high angles $\left(\alpha=0^{\circ}\right.$ and $\left.8^{\circ}\right)$, where two different forcing frequencies are employed at the higher angle for illustrative purposes (fig. 9). At $\alpha=0^{\circ}$, relatively large changes in the aerodynamic coefficients are evident at $C_{\mu} \approx 0.15 \%$ and increasing the forcing amplitude thereafter has little effect. These effects are reflected to some degree in the control authority over the basic vortex characteristics (figs. 10a-10d) where changes are relatively small and authority saturates at a relatively low forcing level. At $\alpha=8^{\circ}$ the effect on $C_{l}$ and hence vortex characteristics is more gradual. Also, the larger separated shear layer represents a larger resource for control and hence the control authority over the vortex is greater. The same would be true at lower angles of attack with greater flap deflections.

\section{Segmented Actuation \& Zonal Control}

Separation control is generally applied over the entire span of a separated region (see above). As a consequence, the control exerted over the vortices is accompanied by significant changes in lift and pitching moment. This is similar to the concerns of other time-dependent control schemes. ${ }^{15,17,34} \mathrm{We}$ address this problem in the following manner: If perturbations are applied locally along some fraction or segment of the slot, it is possible that separation can be achieved over a finite zone of the flap. Then, in principle, the local vortex sheet $\gamma=d \Gamma / d y$ can be varied and hence control can be exerted over a specific vortex, leaving the remainder of the wake unchanged, with considerably smaller excursions in lift and moment. Applying control over different parts of the flap periodically can then facilitate time-dependent control of the vortices by so-called "sloshing" of the lift distribution. Dynamic aspects of this approach are discussed in section IV.E. 
Due to the dearth of separation control data available in a three-dimensional environment, applied over a fraction of the span, we digress slightly here to discuss some details. Consider the application of separation control over the inboard and outboard halves of the slot, where trailing-edge pressures $\left(C_{P, t e}\right)$ corresponding to these two cases are shown in figs. 11a and $11 \mathrm{~b}$, respectively. The pressures indicate the degree of pressure recovery and hence control effectiveness. For the data presented below, segmented actuation was achieved by using the fairing (fig. $2 \mathrm{~d}$ ) to seal the part of the slot not being used. The net result is that active separation control applied on one half of the flap is accompanied by mild passive control on the other half. Control effectiveness clearly increases with increasing $C_{\mu}$ and this can also be seen with respect to the effect on wing $C_{L}$ and $C_{M}$ (fig. 12). Nevertheless, the changes in $C_{L}$ and $C_{M}$ are smaller than when the separation is controlled over the entire flap (cf. fig. 9). A comparison of figs. 11a and $11 \mathrm{~b}$ shows that outboard control is more efficient in attaching the flow, in the sense that smaller $C_{\mu}$ is required for a given maximum pressure recovery. This is consistent with the smaller outboard $C_{\mu}$ required to achieve a given change in the aerodynamic coefficients (fig. 12). Outboard control is also more effective in that the extent over which the pressure recovers is larger even at smaller $C_{\mu}$. This is also true for passive control (fig. 2d), where small changes in the aerodynamic coefficients occur $\left(\Delta C_{L}=0.02, \Delta C_{M}=0.003\right)$ with outboard passive control, while no effect is evident with inboard passive control.

The reason for this difference must somehow be related to the different three-dimensional environment of the two control scenarios. It is suggested here that outboard control is more efficient and effective because the flap-edge vortex aids in the transfer of high-momentum fluid to the surface from below the wing (see schematic in fig. 13a). Hence outboard separation control is the result of a combination of spanwise vortices produced by excitation of the free shear layer superimposed approximately orthogonally on the flap-edge vortex. In contrast, inboard control terminates at the wind tunnel wall-wing junction, where a horseshoe vortex forms at the junction. ${ }^{36}$ Consequently, no fluid can be drawn from the lower part of the wing and it is expected that control effectives will decrease as the separation control perturbations become less two-dimensional as they interact with the junction vortex (see fig. 13b for schematic).

The difference in span loading for inboard and outboard control is shown for the passive case (fig. 14a) and an active case (fig. 14b). The active case was selected such that both inboard and outboard control produce the same $C_{L}$ and $C_{M}$ (see filled symbols in fig. 12 and figs. 14a-14d). The rollup relations predict a relatively small effect of passive control with the exception of the vortex centroid (figs. 15a to 15d). This is due to the relatively large influence on $C_{l}$ in the vicinity of the flap-edge exerted by the passive device, despite the small overall change in lift (see fig. 14a). Active outboard control exerts substantial authority over the all of the vortex characteristics because the vortex sheet is significantly altered in the region where the vortex rolls up. Changes generally have a logarithmic dependence on $C_{\mu}$, with the exception of the vortex centroid, where authority saturates at $C_{\mu} \approx 0.15$. The opposite is true of inboard control because alterations to the vortex sheet occur remotely from flap-edge vortex. The filled symbols in the figures correspond to cases of equal $C_{L}$ and $C_{M}$ (see fig. 12) and thus indicate the degree of control that can be exerted by oscillating between the two scenarios. It should be noted that data corresponding to inboard active control is shifted due to the effect of the passive outboard fairing (fig. 2d) that was employed to seal the outboard part of the slot. The advantage of the active method over the passive one is clearly illustrated here. Active control from different locations can be used to produce precisely the same lift and can exert substantial and varied control over the vortices. Passive methods, on the other hand, operate in a simple on-off manner, thus limiting authority over lift and vortex characteristics.

Seven-hole probe measurements at $x / c=2$ for passive and active control, corresponding to the span-loadings illustrated in figs. 14a and 14b (filled symbols in figs. 12 and 15), are shown in figs. 16 (vorticity and in-plane velocity) and 17 (streamwise velocity). Measured vortex characteristics are compared with those calculated from the rollup relations in table $1 \mathrm{~b}$. In general, the predictions of centroid movement and peak velocity ratio are good, while vorticity and size ratio only show the correct trends. It is interesting to note that simple passive control increases the vortex strength $23 \%$ where this is not evident from the $5 \%$ increase predicted from the span-loading. As observed previously, changes in the axial velocity trends for both passive (fig. 17a, 17b) and active control are consistent with arguments presented in section IV.B.

The rollup relations assume a flat vortex sheet and rollup and thus do not account for the vertical centroid displacements. The overall displacements measured in the wake are shown in the $(y, z)$ map in fig. 18 and indicate that control exerts a non-negligible effect in the vertical $z$-direction. The passive and active control centroids represent data at similar $C_{L}$, while the "No control" and "Full flap control" cases correspond to $\Delta C_{L}=0.17$ (see figs. $12,14 \mathrm{a}$ and 14b). Recall that active inboard control is accompanied by passive outboard control, and vice versa, due to the deployment of the fairing. The maps show that different mode shapes can be directly excited by separation control, but in general this would introduce variation in overall lift. In principle, this can be overcome on a 
configuration that employs more than one flap, where different mode shapes could be excited using control on one flap while overall lift is maintained constant by control on the second flap.

Table 1b. Comparison of inviscid rollup relation predictions with near-wake measurements.

\begin{tabular}{|l|c|c|c|c|}
\hline & \multicolumn{2}{|c|}{ Partial Flap-Passive Control } & \multicolumn{2}{c|}{ Partial Flap-Active Control } \\
\hline & 7-hole Probe & Donaldson-Betz & 7-hole Probe & Donaldson-Betz \\
\hline$\Delta \bar{y} / s(\%)$ & 1.3 & 1.5 & 0.82 & 0.78 \\
\hline$\Gamma^{\prime *} / \Gamma^{\prime}$ & 1.23 & 1.05 & 1.17 & 1.27 \\
\hline$V_{\theta}^{*}(0) / V_{\theta}(0)$ & 1.30 & 1.29 & 1.38 & 1.45 \\
\hline$r_{2}^{*} / r_{2}$ & 0.71 & 0.82 & 0.62 & 0.88 \\
\hline
\end{tabular}

It is of interest to compare the control authority exerted by separation control with that achieved by deflecting a control surface. To examine this, seven-hole data were acquired at $x / c=2$ in the tip vortex region with no flap deflection (see fig. 19a) and with the tip flap deflected $\left(\delta_{i}, \delta_{o}, \delta_{t}\right)=\left(0^{\circ}, 0^{\circ}, 20^{\circ}\right)$ (see fig. 19b). The main effect of deploying the tip flap is to deflect the vortex downwards by $12 \%$ and generate a more symmetric vortex signature. In addition, a weaker counter-rotation vortex is generated from the inboard edge of the tip flap. The lateral displacement of the tip vortex, namely $\Delta \bar{y} / s \approx 1 \%$, is somewhat less than that achieved by separation control.

\section{Outboard Flap Deflection}

\section{Full-Span Flap Control}

The second flap configuration considered was the deflection of the outboard flap $\left(\delta_{i}, \delta_{o}, \delta_{t}\right)=\left(0^{\circ}, 20^{\circ}, 0^{\circ}\right)$ as shown in fig. 1c. This provided an additional counter-rotating inboard vortex in addition to the outboard vortex considered previously. Management of the counter-rotating inboard vortex is considered important due to its prevalence in many vortex alleviation strategies. ${ }^{10,13}$

Figs. 20a-20d show aerodynamic coefficients for the wing which are qualitatively similar to those for the previous case but have two differences: the changes in lift including $C_{L, \max }$ are smaller; and low amplitude excitation $\left(C_{\mu}\right)$ is effective to higher angles of attack. For example, at high amplitude control, local $C_{l}$ and overall $C_{L}$ changes are typically $60 \%$ and $50 \%$ less, respectively (cf. figs. $5 \mathrm{a}$ and $5 \mathrm{~b}$ ). Despite the relatively small changes in lift, separation control exerts considerable authority over the local lift distribution (figs. 21a and 21b), and hence $\gamma$. The effect on lift and moment as a function $C_{\mu}$ is shown in fig. 22 and, unlike the previous case described above, small variations are not proportional to $C_{\mu}$.

More insight into this non-proportionality can be seen from fig. 23, which shows the flap trailing-edge pressures for various forcing amplitudes. At low amplitudes the pressure recovery is mainly evident in the central part of the flap. Although we do not have a definite picture of the degree of separation control, we can note that a small effect is present at the inboard part of flap, while less or no effect is evident at the outboard part of the flap. At $C_{\mu} \approx 0.25$, pressure recoveries are evident at the flap edges, consistent with edge vortices being brought towards the surface, and this is accompanied with renewed increase in lift seen in fig. 22. Further increases in amplitude bring about greater recovery along the entire flap span, but the effects at the inboard and outboard edges saturate at $C_{\mu} \approx 0.5$.

In general, the rollup relations predict a greater effect on the outboard vortex than on the inboard vortex (figs. 24a-24d). As expected, the vortex strength and peak velocity vary in accordance with loading on the flap. However, the centroids do not exhibit the non-proportional behavior and almost full authority is exerted over them for $0.01<C_{\mu}<0.5$, corresponding to a relatively small change in lift: $\Delta C_{L}<0.1$ (fig. 22). Measurements in the wake of the flap at $C_{\mu}=1 \%$ (shown in fig. 25a-25d) are compared with the rollup relations in table 2. In general, the changes to the outboard vortex characteristics are of the same order as those for the combined inboard and outboard flap deflections (c.f. table 1a). It can therefore be concluded that the rollup at the inboard edge of the flap does not significantly affect the near-field rollup of the outboard flap. Rather, it is the local changes in $\gamma$ that most significantly affect the vortex. The main difference between the two cases is that the present lift excursions are smaller due to the smaller flap span. This is important when we attempt to minimize lift excursions, while maintaining vortex control authority (see next section).

Changes to both inboard and outboard vortices are similar when each is referenced to its baseline value. Of note is that the relative strength of the vortices remains constant for baseline and control. A comparison with the rollup relations shows that the inboard vortex trends are not as well predicted. This may be a further limitation of the rollup method, which was not validated for counter-rotating vortices. ${ }^{35}$ 
Table 2. Effect of separation control on the midspan flap trailing vortices.

\begin{tabular}{|c|c|c|c|c|}
\hline & \multicolumn{2}{|c|}{ Outboard Vortex } & \multicolumn{2}{c|}{ Inboard Vortex } \\
\hline & 7-hole probe & Donaldson-Betz & 7-hole probe & Donaldson-Betz \\
\hline$\Delta \bar{y} / s(\%)$ & -2.32 & -2.07 & 2.62 & 0.93 \\
\hline$\Gamma^{\prime *} / \Gamma^{\prime}$ & 1.36 & 1.35 & 1.35 & 1.76 \\
\hline$V_{\theta}^{*}(0) / V_{\theta}(0)$ & 1.44 & 1.82 & 1.08 & 1.97 \\
\hline$r_{2}^{*} / r_{2}$ & 0.49 & 0.74 & 0.57 & 0.90 \\
\hline
\end{tabular}

\section{Segmented Actuation}

In our quest to maintain vortex control authority while simultaneously minimizing lift and moment excursions, perturbations were introduced from specific fractions of the outboard flap. The cases considered included three separate span fractions, each being one half of the flap span (cf. section IVC): namely inboard, outboard and midspan of the flap (see schematic in fig 26a).

Introducing control from the different locations results in relatively small overall changes to the aerodynamic indicators (fig. 26b). This is most evident for outboard and inboard control, where $\Delta C_{L} \approx 0.035$ and $\Delta C_{M} \approx 0.008$ over the full range of control amplitude, while mid-span perturbations result in the largest changes to the aerodynamic indicators. Despite the small overall changes, separation is very effectively controlled, as can be seen by the pressure recoveries associated with both inboard and outboard perturbations (fig. 27a) as well as the significantly different span-loadings (27b). Thus significant control is applied locally to the vortex sheet and this manifests as effective authority over both inboard and outboard vortices (figs. 28a-28h).

It is believed that the increase in bound circulation (lift) that accompanies separation control in two-dimensional flows is "lost" to the vortices when control is applied near the flap edges. Less of this circulation is lost when control is applied remotely from the edges. Thus, control applied near the edges has the potential for significant vortex control accompanied by a negligible effect on the overall aerodynamic forces.

Wake measurements are shown in figs. 29a-29c and overall comparison of the vortex characteristics are shown in tables $3 \mathrm{a}$ and $3 \mathrm{~b}$. It is immediately obvious that control in the vicinity of the flap edge results in full control authority, for both the outboard (table 3a) and inboard (table 3b) vortices. As previously stated, the rollup predictions are inferior for the inboard vortex. Thus, for almost identical lift, the ratio of inboard to outboard vortex strength can be varied from 0.55 (outboard control) to 0.87 (inboard control). In fact, the peak inboard vorticity is more than double the outboard peak with inboard control (fig. 29b).

Table 3a. Effect of segmented separation control on the outboard vortex trailing the midspan flap.

\begin{tabular}{|c|c|c|c|c|c|c|}
\hline & \multicolumn{2}{|c|}{ Inboard Control } & \multicolumn{2}{c|}{ Outboard Control } & \multicolumn{2}{c|}{ Midspan Control } \\
\hline & Wake & Rollup & Wake & Rollup & Wake & Rollup \\
\hline$\Delta \bar{y} / s(\%)$ & -0.34 & -0.48 & -2.50 & -2.21 & -1.22 & -1.27 \\
\hline$\Gamma^{\prime *} / \Gamma^{\prime}$ & 1.03 & 1.09 & 1.24 & 1.05 & 1.17 & 1.33 \\
\hline$V_{\theta}^{*}(0) / V_{\theta}(0)$ & 0.94 & 1.17 & 1.54 & 1.36 & 1.17 & 1.65 \\
\hline$r_{2}^{*} / r_{2}$ & 0.89 & 0.93 & 0.44 & 0.77 & 0.92 & 0.80 \\
\hline
\end{tabular}

Table 3b. Effect of segmented separation control on the inboard vortex trailing the midspan flap.

\begin{tabular}{|c|c|c|c|c|c|c|}
\hline & \multicolumn{2}{|c|}{ Inboard Control } & \multicolumn{2}{c|}{ Outboard Control } & \multicolumn{2}{c|}{ Midspan Control } \\
\hline & Wake & Rollup & Wake & Rollup & Wake & Rollup \\
\hline$\Delta \bar{y} / s(\%)$ & 2.73 & 1.38 & 0.09 & -0.38 & -0.44 & -0.79 \\
\hline$\Gamma^{\prime *} / \Gamma^{\prime}$ & 1.32 & 1.38 & 1.01 & 1.19 & 1.12 & 1.70 \\
\hline$V_{\theta}^{*}(0) / V_{\theta}(0)$ & 1.25 & 1.61 & 0.85 & 1.18 & 0.88 & 1.67 \\
\hline$r_{2}^{*} / r_{2}$ & 0.41 & 0.86 & 0.91 & 1.01 & 1.09 & 1.01 \\
\hline
\end{tabular}




\section{E. Dynamic Vortex Management}

One of the objectives of wake management involves the direct excitation of instabilities in the wake, designed to reduce the time to their interaction and mutual destruction. Data presented in sections IV.C and D showed that the main vortex characteristics can be varied in a quasi-steady manner. This corresponds to excitation with an arbitrarily long wavelength. By controlling vortices in this manner we are dealing with two main frequencies: the frequency at which we control separation $\left(f_{e}\right)$ and the frequency at which we control the vortices $\left(f_{w}\right)$. Wake instabilities wavelengths $\left(\lambda=U_{\infty} / f_{w}\right)$ are typically $\mathrm{O}(b)$ or larger, while separation control frequencies are $\mathrm{O}\left(U_{\infty} / L_{f}\right)$. We therefore find a fortuitous disparity between the two frequencies, $f_{w}<<f_{e}$.

The question addressed empirically in this section is how fast the vortices can be excited by separation control, i.e. what is $f_{w, \max }$ or, equivalently, what is the shortest wavelength $\left(\lambda_{\min }\right)$ for which we maintain full control authority. This depends directly on the time-scales characterizing dynamic separation $\left(T_{s}\right)$ and attachment $\left(T_{a}\right)$. The time taken for the flow to fully attach to, or separate from, a surface differs depending on the location on the wing, but it has been noted in previous investigations that downstream of the control location $T_{s} \approx T_{a}{ }^{26,39}$ Also, $T_{s}$ and $T_{a}$ are typically 10 to 20 times larger than the separation control time-scales $1 / f_{e}$. These observations were exploited in the context of dynamic stall control on a pitching airfoil. ${ }^{40}$ With this as background we note that the full control authority cannot be achieved faster than $T_{s}+T_{a}$ or:

$$
f_{w, \max } \leq \frac{1}{T_{s}+T_{a}}
$$

For convenience we write the wake frequency and flap length in dimensionless form: $k=f_{w} L_{f} / U_{\infty}$ and $\xi=L_{f} / c$, and note that maximum dimensionless wake frequency for full control authority is $k_{\max }=f_{w, \max } L_{f} / U_{\infty}$. Using the above definitions, we can express the dimensionless wavelength as

$$
\lambda / b=\xi / k A R
$$

and thus the smallest wavelength for full control authority is $\lambda_{\min } / b=\xi / k_{\max } A R$

We proceed to find $\lambda_{\min }$ empirically by amplitude modulating the perturbations in a "burst-mode" mode at frequencies $f_{w}<f_{e}$. Dynamic pressures on the wing are phase-averaged and the procedure is repeated for successively higher $f_{w}$. For illustrative purposes, we show the signal used to drive the voice-coil actuators (described in section II) at $f_{w}=4 \mathrm{~Hz}, 10 \mathrm{~Hz}$, and $20 \mathrm{~Hz}$, where $f_{e}$ corresponds to $F^{+}=0.79$ (fig. 30). Upper surface, mid-span $C_{P}$ 's are shown at $x / c=0.006,0.3,0.705$ (immediately downstream of the flap-shoulder slot) and 1.0. When actuation is initiated or terminated, the upper surface pressures respond as the boundary layer either attaches to, or detaches from, the surface. This is shown, by way of example for $f_{w}=4 \mathrm{~Hz}$ and $10 \mathrm{~Hz}$ in figures $31 \mathrm{a}$ and $31 \mathrm{~b}$, respectively. The relatively large high frequency oscillations $\left(f_{e}\right)$ near the flap shoulder and trailing edge are due to the coherent initiation, amplification and advection of the separation control vortices. These oscillations are much reduced upstream due to their being located remotely from the forcing slot. For all $x / c$ locations indicated, minimum and maximum $C_{P}$ data can be discerned, as illustrated with respect to the $x / c=1$ location in figs. $31 \mathrm{a}$ and $31 \mathrm{~b}$.

The maximum and minimum $C_{P}$ data are shown in figs. $32 \mathrm{a}$ and $32 \mathrm{~b}$ as a function of $\lambda$ calculated according to eqn. $11(A R=4$ and $\xi=0.3)$ for the trailing-edge $(x / c=1)$ and leading-edge $(x / c=0.006)$, respectively. Also shown are the conditions where no control (baseline) is applied and the condition where control is applied in a "time invariant" manner (no modulation). Trailing edge $C_{P}$ 's show that the baseline-to-control excursions are exceeded when the actuators are deployed in burst mode, due to pressure overshoots that are associated with dynamic separation and control. With increasing $f_{w}$ (decreasing $\lambda / b$ ), the trailing-edge control authority is maintained up to the highest frequency tested, corresponding to $\lambda / b \approx 0.5$.

The leading-edge minimum and maximum $C_{P}$ data also exhibit overshoots, but only for $\lambda / b>3$ (see Fig. 32b). Similar results were observed at $x / c=0.3$ and the difference in pressure between controlled and baseline cases $\left(C_{P, \min }-C_{P, \max }\right)$ are an indication of lift fluctuations. Consequently, with increasing $f_{w}$ the lift oscillations reduce while the mean lift increases, as the $C_{P \text {,mean }}$ tends towards a lower value. Thus, the overall lift on the wing increases, but the lift oscillations decrease.

\section{Concluding Remarks}

The concept and viability of managing vortices trailing wing flaps by means of active and passive separation control, was demonstrated experimentally. Separation control was found to have a marked effect on vortex location, 
strength, tangential velocity, axial velocity and size over a wide range of flap deflections, angles of attack and control conditions. In many instances the quantitative vortex characteristics were well predicted by the inviscid rollup relations. Separation control applied near the flap edges exerted significant control over either outboard or inboard edge vortices while producing relatively small lift and moment excursions. The large disparity between the scales characterizing dynamic separation control (fraction of flap chord) and those characterizing wake instabilities (multiple of wing-span), facilitated perturbation of the vortices from arbitrarily long wavelengths down to wavelengths less than a typical wingspan. The method is now in a position to be tested in a wind tunnel with a longer test section, a tow tank, or even on a light aircraft.

It is believed that this method will have significant appeal from an industry perspective due its retrofit potential with no impact on cruise (separation control devices are tucked away in the cove); low operating power requirements (separated flow instabilities are exploited); small lift oscillations when deployed in a dynamic manner; and significant flexibility (application to different high-lift systems or different flight conditions).

\section{Acknowledgments}

This work was performed while the author held a National Research Council-NASA Langley Research Center Associateship. The author wishes to thank W. L. Sellers III, A. E. Washburn, M. J. Walsh, L. P. Melton, L. N. Jenkins, D. H. Neuhart, J. C. Lin, G. S. Jones, S. A. Gorton, G. C. Greene, M. R. Khorrami, I. J. Wygnanski (University of Arizona) and H. M. Nagib (IIT, Chicago) for their active assistance and many fruitful discussions. The author also wishes to thank R. D. White, A. Barnes and R. L. Clark for their exceptional technical support.

\section{References}

1. Green, S. I., "Wing Tip Vortices," in "Fluid Vortices," Green, S. I. (ed.), Kluwer Academic Press, Ch. 1, pp. 1-33, 1995.

2. Spalart, P. R., (1998) "Airplane trailing vortices," Annual Review of Fluid Mechanics, Vol. 30: 107-138.

3. Rossow V. J. (1999) "Lift-generated vortex wakes of subsonic transport aircraft," Progress in Aerospace Sciences, Volume 35, Issue 6, Pages 507-660.

4. Crouch, J. D., Miller, G. D. and Spalart, P. R. (2001) “Active-Control System for Breakup of Airplane Trailing Vortices,” AIAA Journal, Vol. 39, No. 12, pp. 2374-2381.

5. Robinson, J. J., "A simulation-based study of the impact of aircraft wake turbulence weight categories on airport capacity," CP-584, AGARD, 1996, pp. 22-1-22-15.

6. Dunham, Jr., R. E., "Unsuccessful Concepts For Aircraft Wake Vortex Minimization," Proceedings Wake Vortex Minimization Symposium, NASA, SP-409, 1977, pp. 221-250.

7. Rossow, V. J., "Prospects for alleviation of hazard posed by lift-generated wakes," Proceedings of the Aircraft Wake Vortices Conf., DOT/FAA/SD-92/1.1, 1991, pp. 22-1 - 22-40.

8. Scorer R.S., "Natural Aerodynamics," Pergamon, New York, 1958.

9. Crow, S. C., (1970) "Stability theory for a pair of vortices," AIAA Journal, Vol. 8, pp. 2172-2179.

10. Rennich, S. C. and Lele, S. K., "Method for Accelerating the Destruction of Aircraft Wake Vortices," AIAA Journal of Aircraft, Vol. 36, No. 2, 1999, pp. 398-404.

11. Rossow, V. J. "Theoretical study of lift-generated vortex wakes designed to avoid rollup," AIAA Journal, Vol. 13, No. 4, 1975, pp. 476-484.

12. Cliffone, D. L. and Orloff, K. L., "Far field wake-vortex characteristics of wings," AIAA Journal of Aircraft, Vol. 12, No. 5, 1975, pp. 464-470.

13. Ortega, J. M., Bristol R. L. and Savas, Ö., "Experimental study of the instability of unequal-strength counter-rotating vortex pairs" J. Fluid Mech., Vol. 474, 2003, pp. 35-84.

14. Crow, S. C., "Panel Discussion," in Aircraft Wake Turbulence and Its Detection, edited by J. H. Olsen, A., Goldburg, and M. Rogers, 1971, Plenum Press, New York, pp. 580-582.

15. Crow, S. C. and Bate E. R., "Lifespan of trailing vortices in a turbulent atmosphere," Journal of Aircraft, Vol. 13, No 7, 1976, pp. 476-82.

16. Bilanin, A. J., and Widnall, S. E., "Aircraft wake dissipation by sinusoidal instability and vortex breakdown," AIAA Paper 73-107, 1973.

17. Crouch, J. D., "Forcing the breakup of airplane trailing vortices," Conference on Capacity and Wake Vortices, Imperial College of Science, Technology and Medicine, London, England, September 2001.

18. Rudolph, P. K. C. (1996) "High-lift systems on commercial subsonic airliners," NASA CR 4746.

19. van Dam, C. P., "The aerodynamic design of multi-element high-lift systems for transport airplanes," Progress in Aerospace Sciences, Volume 38, pp. 101-144, 2002.

20. de Bruin, A.C., Hegen, S.H., Rohne, P.B. and Spalart, P.R., "Flow field survey in the trailing vortex system behind a civil aircraft model at high lift," AGARD-CP-584, 1996, pp. 25-1 to 25.12.

21. Bellastrada, C., Breitsamter, C. and Laschka, B, "Investigation of turbulent wake vortex originating from a large transport aircraft in landing configuration," Proc. CEAS Aerospace Aerodynamics Research Conference, 2002, pp 31.1-31.10.

22. Crouch J. D., "Instability and transient growth for two trailing-vortex pairs," J. Fluid Mech., vol. 350, 1997, pp. $311-330$.

12

American Institute of Aeronautics and Astronautics Paper 2005-0061 
23. Rumsey, C.L. and Ying, S.X., "Prediction of high lift: review of present CFD capability," Progress in Aerospace Sciences Vol. 38, Issue 2, 2002, pp. 145-180.

24. Lin, J.C., "Review of research on low-profile vortex generators to control boundary-layer separation," Progress in Aerospace Sciences, Vol. 38, Issue. 4, 2002, pp. 389-420.

25. Greenblatt, D. and Wygnanski, I, "Control of separation by periodic excitation," Progress in Aerospace Sciences, Volume 37, Issue 7, pp. 487-545, 2000.

26. Greenblatt, D., Nishri, B., Darabi, A. and Wygnanski, I., "Dynamic stall control by periodic excitation. Part 2: Mechanisms," AIAA Journal of Aircraft, Vol. 38, No. 3, 2001, pp. 439-447.

27. Betz, A., "Behavior of vortex systems," Zeit. für angewandte Math. und Mech., Vol. 12, No. 3, June 1932. See NACA TM 713, June 1933.

28. Donaldson, C duP., Snedeker, R. S. and Sullivan, R. D., "Calculation of aircraft wake velocity profiles and comparison with experimental measurements," AIAA Journal of Aircraft, Vol. 11, No. 9, 1974, pp. 547-555.

29. Yates, J.E., "Calculation of initial vortex roll-up in aircraft wakes," AIAA Journal of Aircraft, Vol. 11, No. 7, 1974, pp. 397-400.

30. McAlister, K. W. and Takahashi, R. K. "NASA 0015 wing pressure and trailing vortex measurements" NASA TP 3151 (AVSCOM Technical Report 91-A-003), November 1991.

31. Spivey, W. A. and Morehouse, G. G., "New insights into the design of swept-tip rotor blades," $26^{\text {th }}$ National Annual Forum Proceesdings of the American Helicopter Society, Washington, D.C., 1970.

32. Batchelor G.K., "Axial flow in trailing line vortices," J. Fluid Mech., 1964, Vol. 20, part 2, pp. 645-58.

33. Green, S. I., "Introduction to Vorticity," in "Fluid Vortices," Green, S. I. (ed.), Kluwer Academic Press, Ch. 10, pp. 427$470,1995$.

34. Chevalier H., "Flight test studies of the formation and dissipation of trailing vortices," Journal of Aircraft, Vol.10, No. 1, pp. 14-18.

35. Donaldson, C duP., Snedeker, R. S. and Sullivan, R. D., "Calculation of the wakes of three transport aircraft in holding, takeoff and landing configurations, and comparison with experimental measurements" A.R.A.P. Report No. 190, 1973, AFSOR-TR-73-1594.

36. Simpson, R. L., "Junction flows," Annual Review of Fluid Mechanics, 2001. Vol. 33, pp. 415-443.

37. Moore, D.W. and Saffman, P.G., "Axial flow in laminar trailing vortices," Proc. R. Soc., London Ser. A 333, 1973, pp. 491-508.

38. Widnall, S.E. "The Structure and Dynamics of Vortex Filaments," Annual Review of Fluid Mechanics Vol. 7 (1975), pp. 141-165.

39. Greenblatt, D., Darabi, A., Nishri, B. and Wygnanski, I. "Separation control by periodic addition of momentum with particular emphasis on dynamic stall," American Helicopter Society Paper T3-4, Gifu, Japan, April 21-23, 1998.

40. Greenblatt, D., Neuburger, D., Wygnanski, I., "Dynamic Stall Control by Intermittent Periodic Excitation," AIAA Journal of Aircraft, Vol. 38, No. 1, 2001, pp. 188-190.

\section{Appendix A: Pressure Interpolation}

The model is equipped with 165 static pressure ports arranged in a perpendicular spanwise and chordwise grid. The spanwise ports are located on the upper surface at the chordwise locations $x / c=5 / 100,3 / 10,77 / 100$, and 1 , and are grouped more closely near the tip. The chordwise ports are located at spanwise locations $y / s=1 / 6,1 / 2,5 / 6$ and 99/100, around the perimeter of the wing, and are grouped more closely near the leading-edge.

In order to estimate the wing span-loading more accurately, a three-dimensional interpolation method was employed to determine the chordwise pressures at each of the spanwise locations. Fig. A1 shows locations of pressure ports where the filled symbols represent measured pressures and the open symbols represent interpolated pressures. The interpolation at point $(2,2)$ is performed using the equation of a plane through measured pressures at $(1,1),(1,2)$, and $(2,1)$, namely:

$$
C_{P 2,2}=\frac{C_{P 2,1}-C_{P 1,1}}{x_{2,1}-x_{1,1}}\left(x_{2,2}-x_{1,1}\right)+\frac{C_{P 1,2}-C_{P 1,1}}{y_{1,2}^{*}-y_{1,1}^{*}}\left(y_{2,2}^{*}-y_{1,1}^{*}\right)+C_{P 1,1}
$$

When the interpolated points are arranged in rectangular grid as shown, equation (A1) reduces to:

$$
C_{P 2,2}=C_{P 2,1}-C_{P 1,1}+C_{P 1,2}
$$

Similarly, planes are fitted to pressures at points $(4,1),(5,1)$, and $(5,2)$ to obtain those at $(4,2)$, and $(3,2)$ is determined by direct interpolation. An identical procedure to that described above is performed using the pressures at $(1,5)$ to $(5,5)$ to obtain those at $(1,4)$ to $(5,4)$. Finally, pressures at $(1,3)$ to $(5,3)$ are obtained by direct interpolation. 


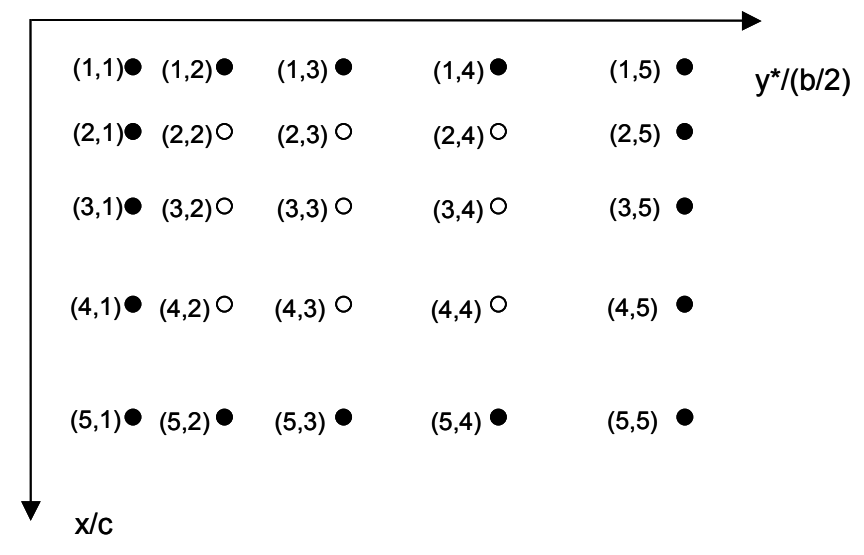

Fig. A1. Schematic illustrating the pressure interpolation method.

\section{Appendix B: Closed Form Donaldson-Betz Vortices}

To obtain closed form expressions for eqns. 1-4, we assume that the lift, or circulation, distribution in the intermediate vicinity of the flap interface is of the form:

$$
\Gamma=a_{0}+a_{1} y+a_{2} y^{2}+a_{3} y^{3}
$$

and fit a least squares curve to the experimental data in the vicinity of the flap edge. Consequently, from $|d \Gamma / d y|_{\max }$ we find that the vortex inception is:

$$
y_{\max }=-\frac{a_{2}}{3 a_{3}}
$$

and the limits of integration, namely the adjacent local minima in $|d \Gamma / d y|$, are:

$$
y_{A, B}=\frac{-a_{2} \pm \sqrt{a_{2}^{2}-3 a_{1} a_{3}}}{3 a_{3}}
$$

From equation (1), the vortex strength is:

$$
\Gamma^{\prime}=a_{1} \delta y+a_{2} \delta y^{2}+a_{3} \delta y^{3}
$$

where the shorthand notation $\delta y^{j} \equiv y_{B}^{j}-y_{A}^{j}, j=1,2,3$ is introduced for convenience.

From equation (2), the centroid of the rolled-up vortex is at:

$$
\bar{y}=\frac{\frac{a_{1}}{2} \delta y^{2}+\frac{2 a_{2}}{3} \delta y^{3}+\frac{3 a_{3}}{4} \delta y^{4}}{a_{1} \delta y+a_{2} \delta y^{2}+a_{3} \delta y^{3}}
$$

From equation (3), the "size" of the vortex is:

$$
r_{2} \approx \frac{1}{3 a_{3}} \sqrt{a_{2}^{2}-3 a_{1} a_{3}}
$$

Finally, from equation (4), the peak velocity at the center of an inviscid vortex is:

$$
V_{\theta}(0)=-\frac{1}{\pi}\left(a_{1}-\frac{a_{2}^{2}}{3 a_{3}}\right)
$$



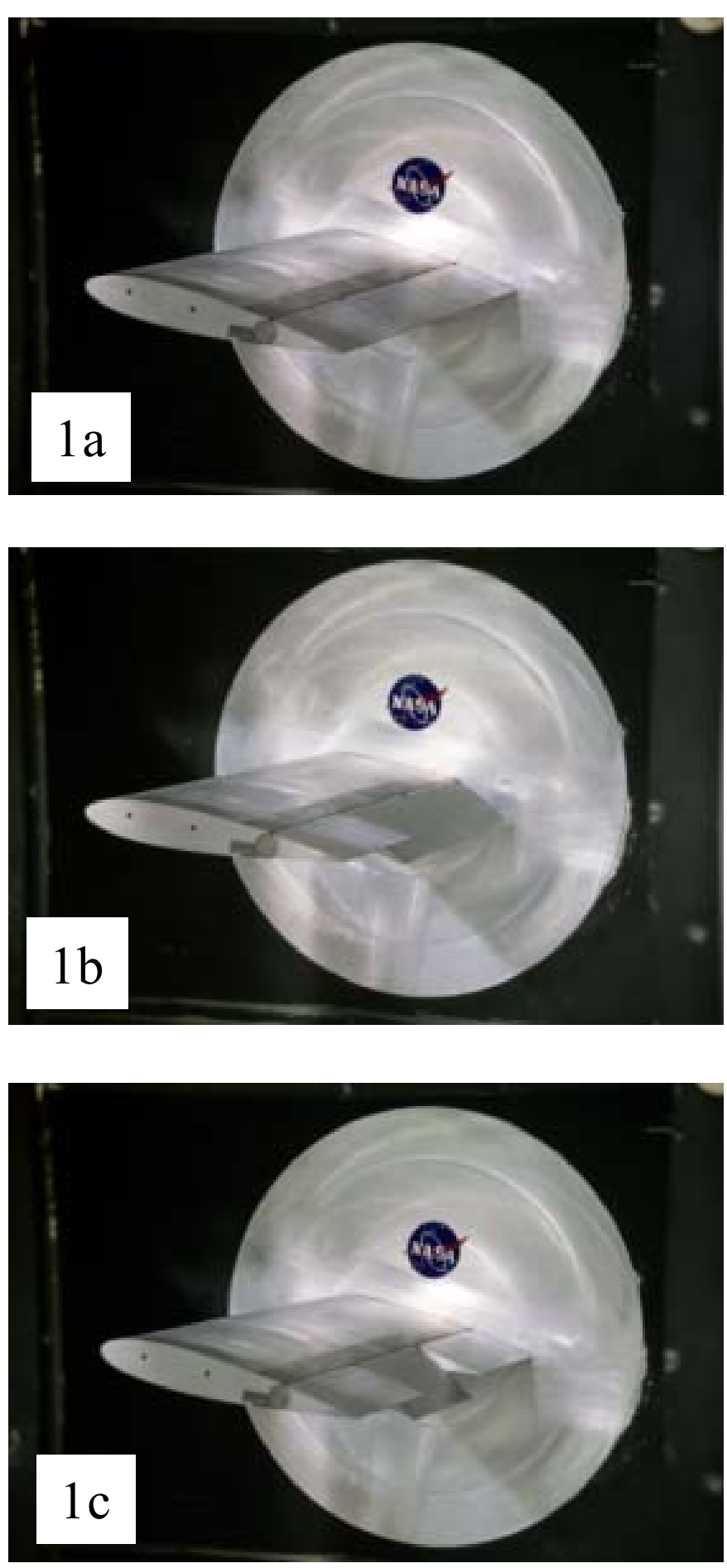

Fig. 1. Photographs of the semi-span wing model showing: (a) no flap deflections; (b) deflection of the inboard and outboard flaps; (c) deflection of the outboard flap.

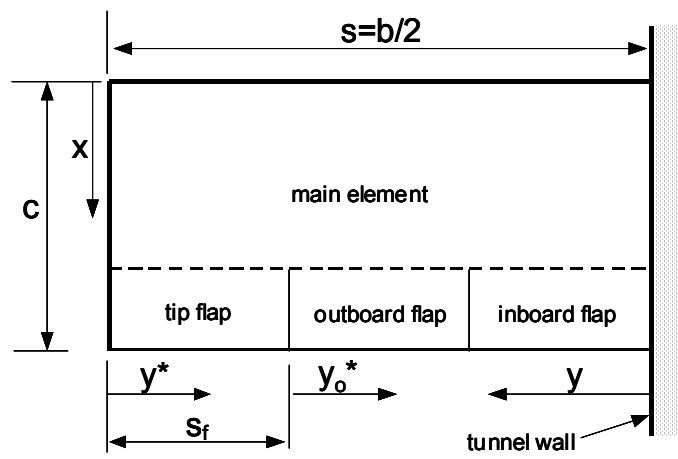

(a)
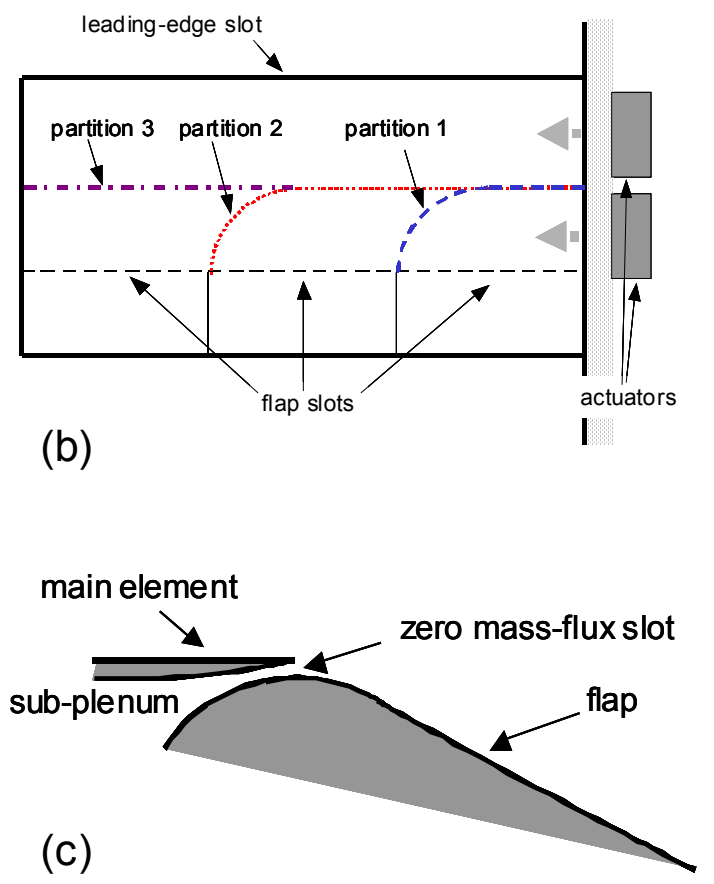

(d)

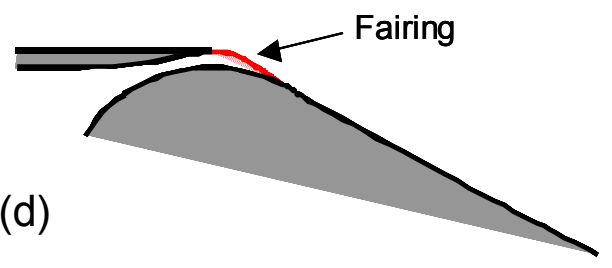

Fig. 2 (a) Schematic showing the semi-span model coordinate systems and definitions; (b) cutaway view of the top of the wing, showing the placement of partitions used for exciting the different zero mass-flux slots; (c) close-up section of the flap-slot region illustrating the technique used to introduce zero mass-flux perturbations; (d) close-up section of the flap-slot region showing the fairing used for passive separation control. 

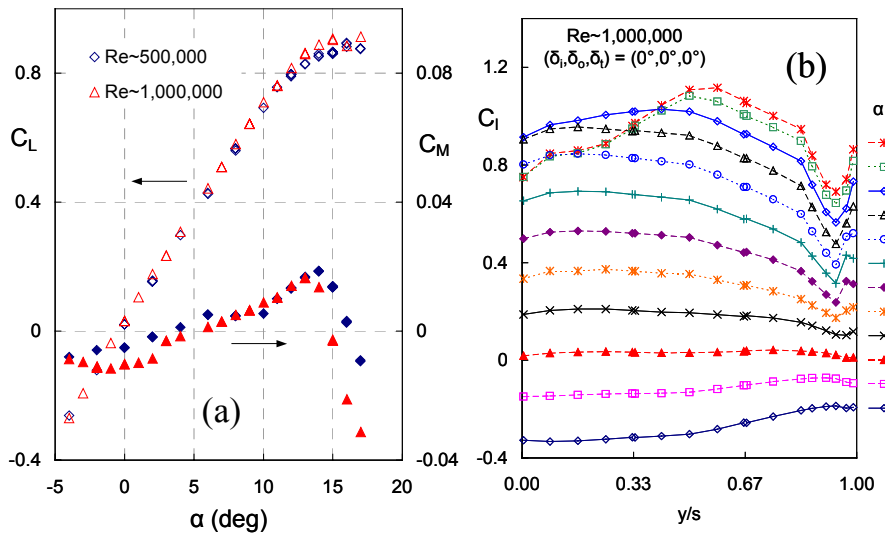

Fig. 3 (a) Unflapped wing lift and moment coefficients for the two Reynolds numbers considered; (b) wing spanloading illustrating formation of the tip vortex on the wing and inboard stall.
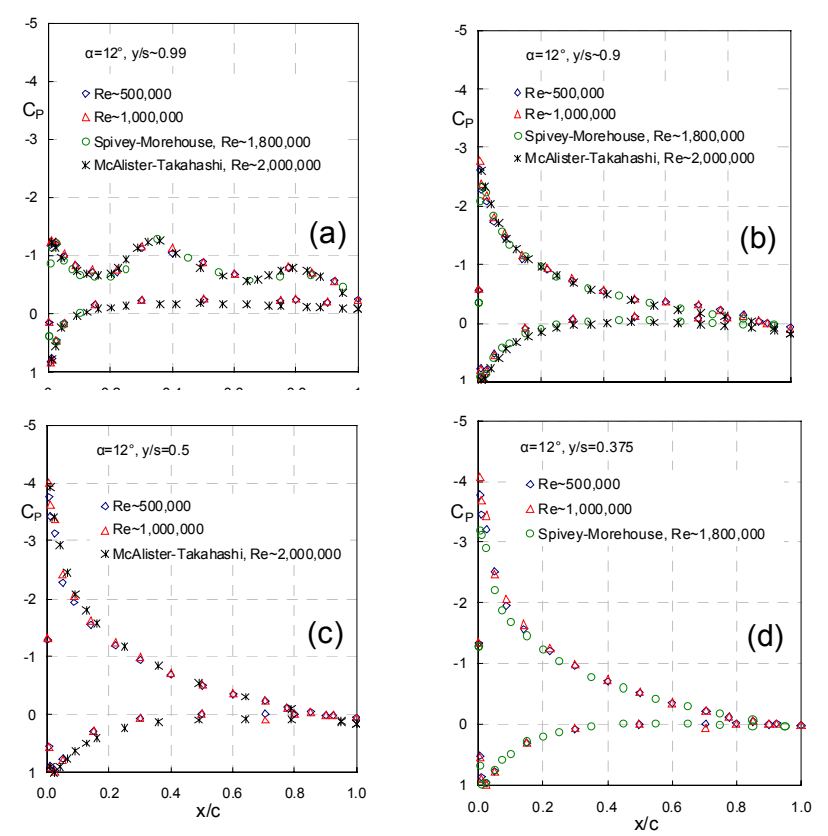

Fig. 4. Sectional pressure distributions compared with previous investigations at higher Reynolds numbers. (Data courtesy of $K$. W. McAlister, NASA Ames Research Center).
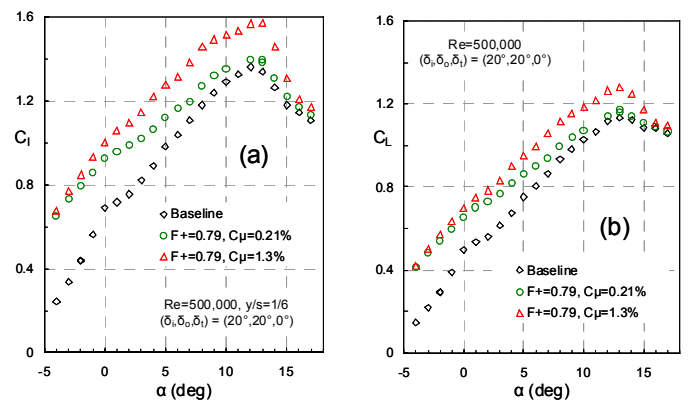

Fig. 5. (a) Inboard lift coefficient and (b) wing lift coefficient for two forcing amplitudes with inboard and outboard flaps deflected.
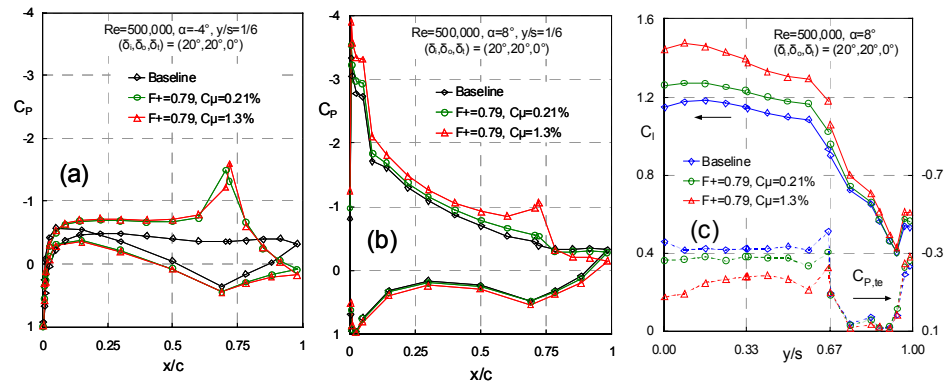

Fig. 6. Inboard pressure distributions for (a) relatively low; (b) relatively high angles of attack; and (c) span loading with and without active flow control over the entire span of the inboard and outboard flaps.
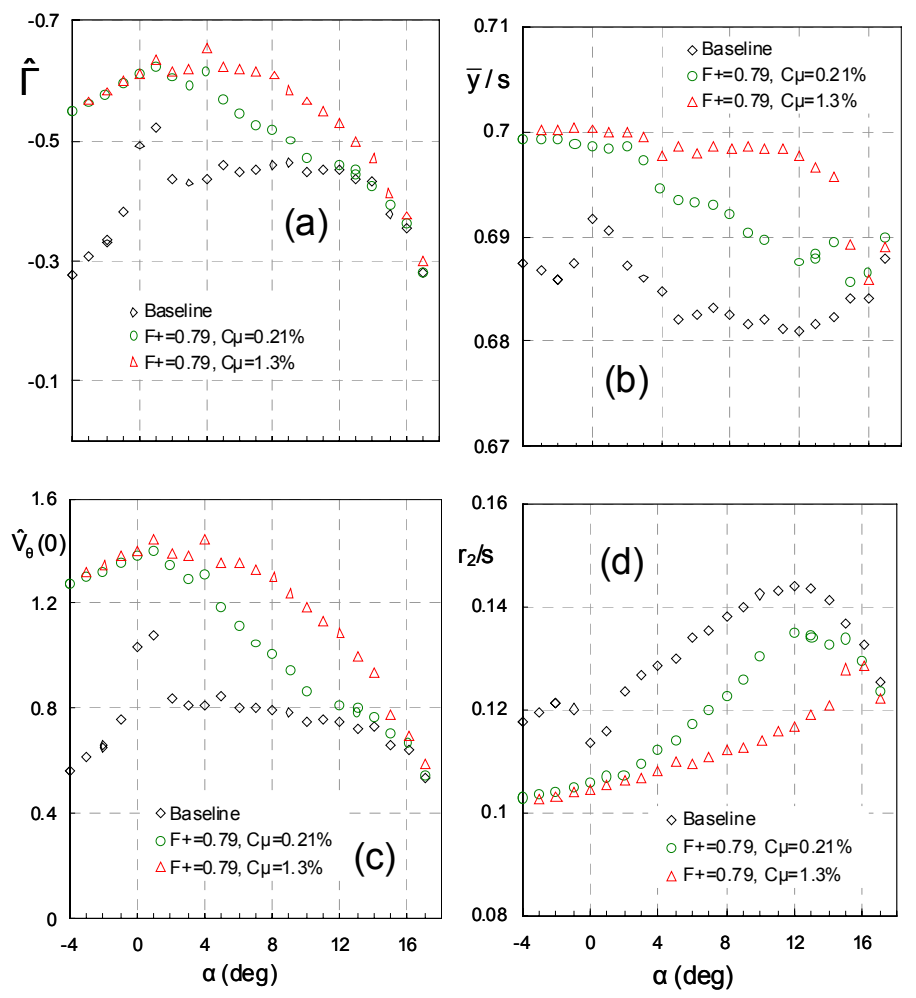

Fig. 7. Donaldson-Betz predictions of vortex characteristics, using experimentally determined span-loading, namely (a) vortex strength; (b) centroid; (c) Peak velocity; and (d) outer size. 

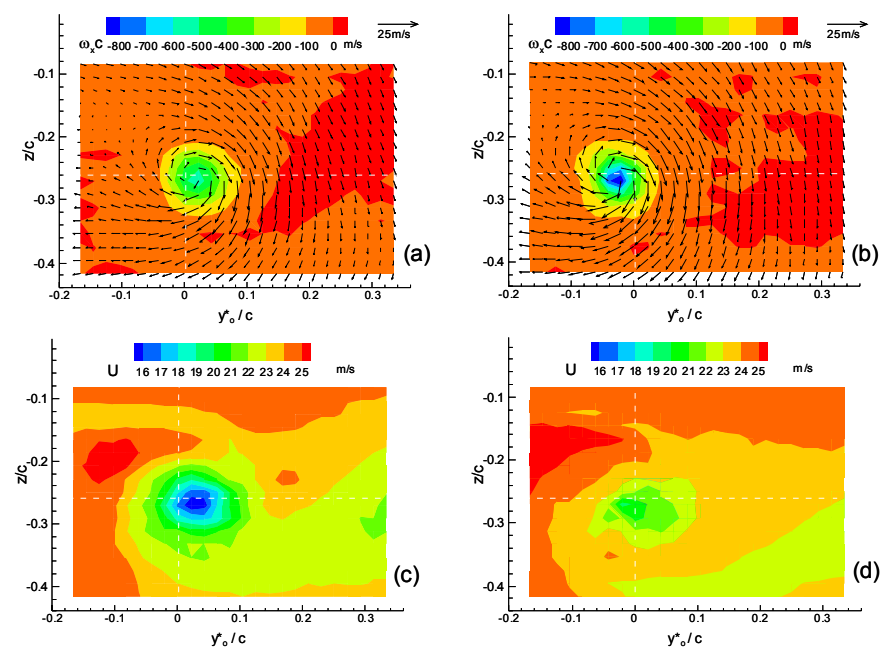

Fig. 8. Seven-hole probe measurements of axial vorticity and inplane velocity for (a) baseline and (b) control scenarios $(x / c=2)$; seven-hole probe measurements of axial velocity for (c) baseline and (d) control scenarios $(x / c=2)$.
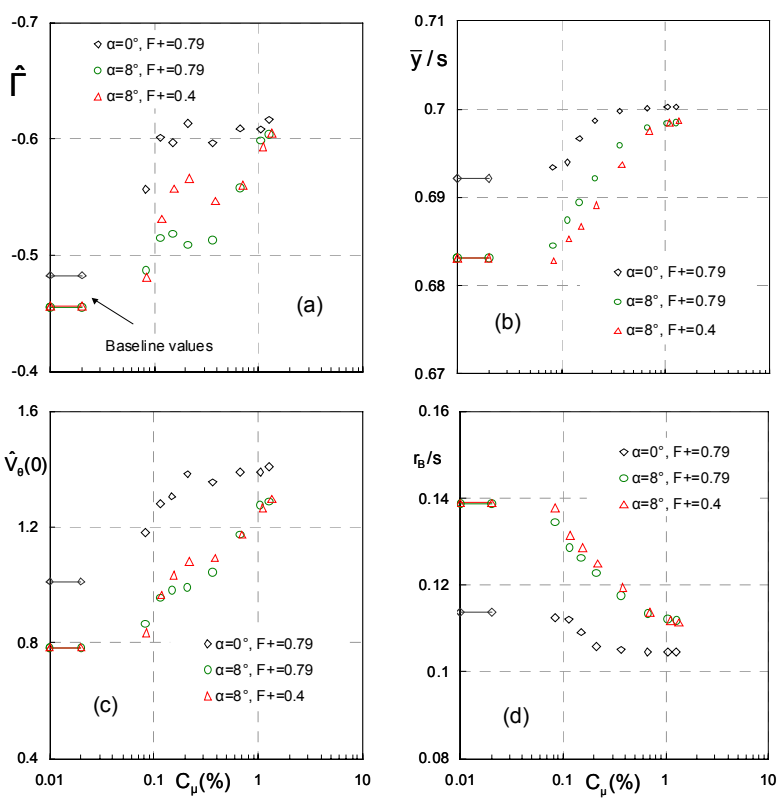

Fig. 10. Donaldson-Betz predictions of vortex characteristics as a function of forcing amplitude corresponding to the data in fig. 9.
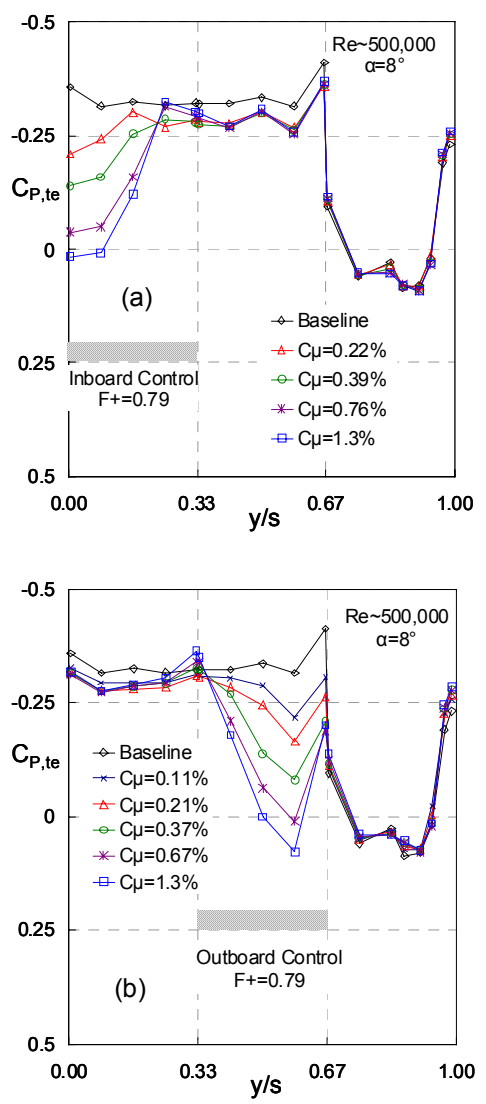

Fig. 11. Spanwise flap trailing-edge pressure recovery for (a) inboard separation control and (b) outboard separation control at the $\left(\delta_{i}, \delta_{o}, \delta_{t}\right)=\left(20^{\circ}, 20^{\circ}, 0^{\circ}\right)$ configuration. 


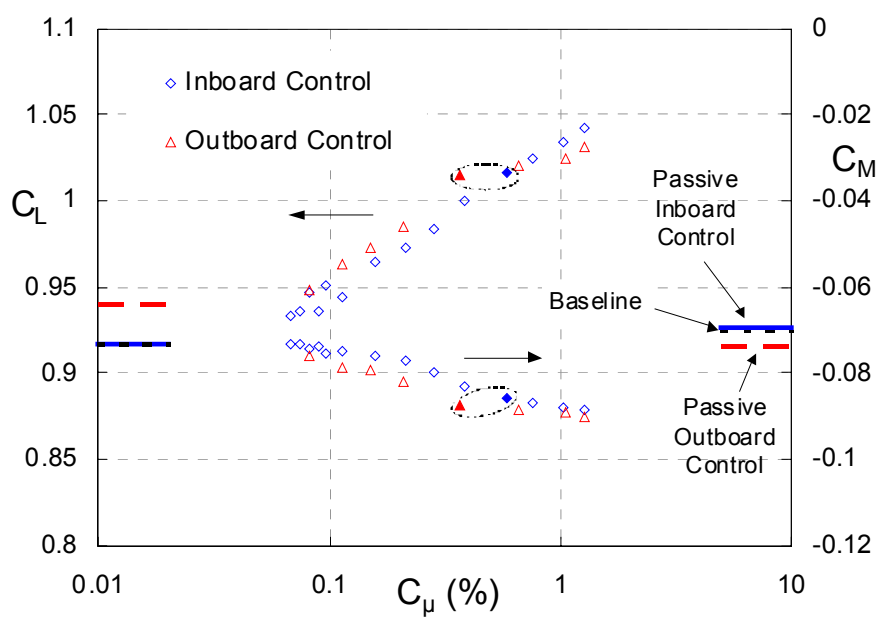

Fig. 12. Effect of passive and active, inboard and outboard, separation control on overall wing lift and moment coefficients.
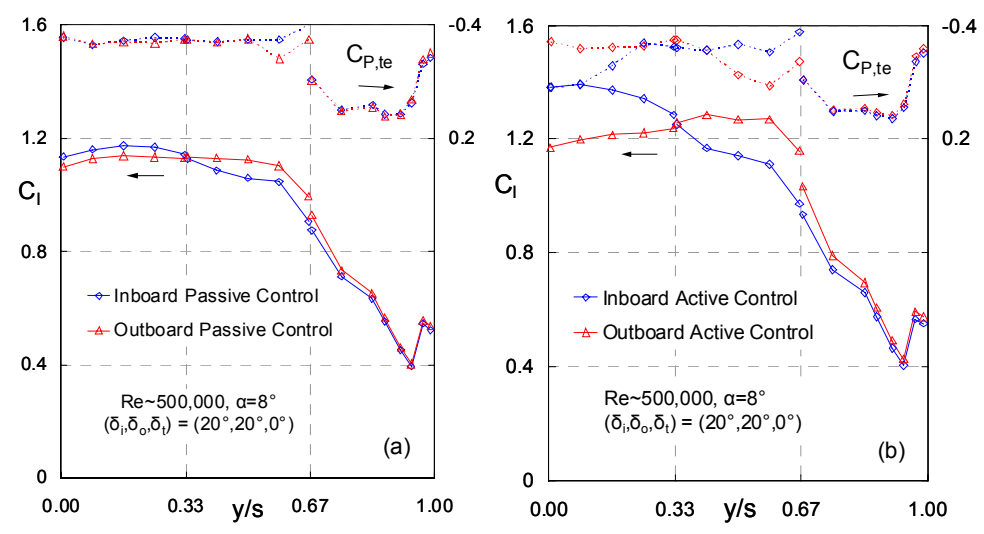

Fig. 14. Span-loading for (a) passive and (b) active inboard and outboard control.
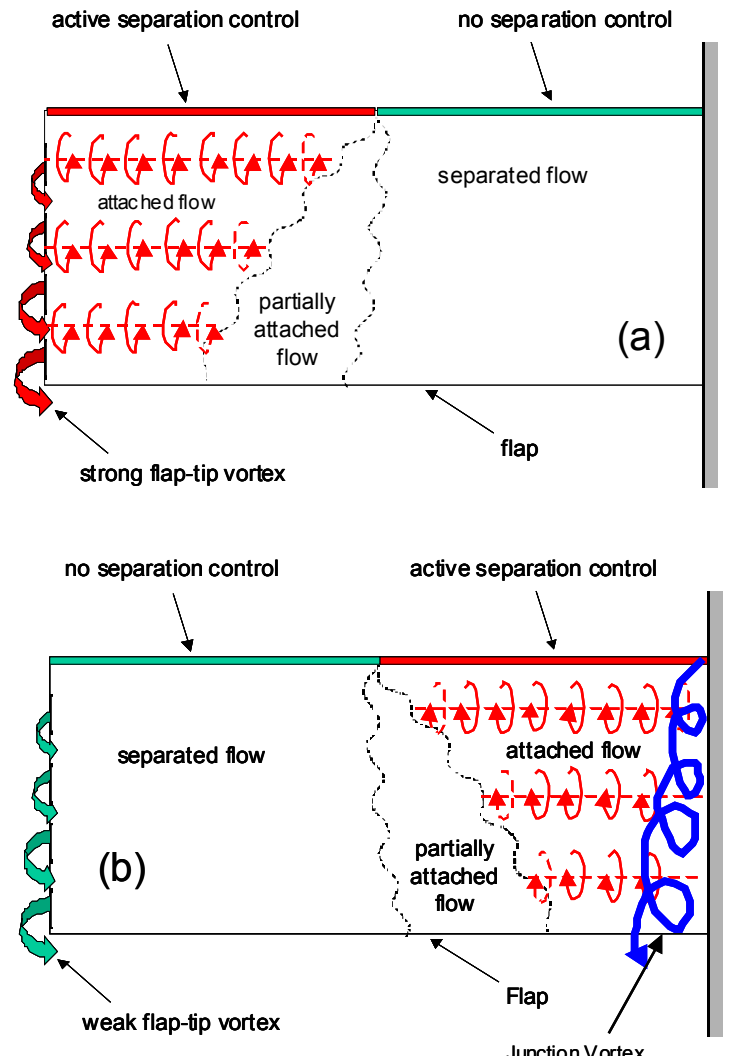

Fig. 13. Schematic illustrating the difference between outboard and inboard separation control on a flap.
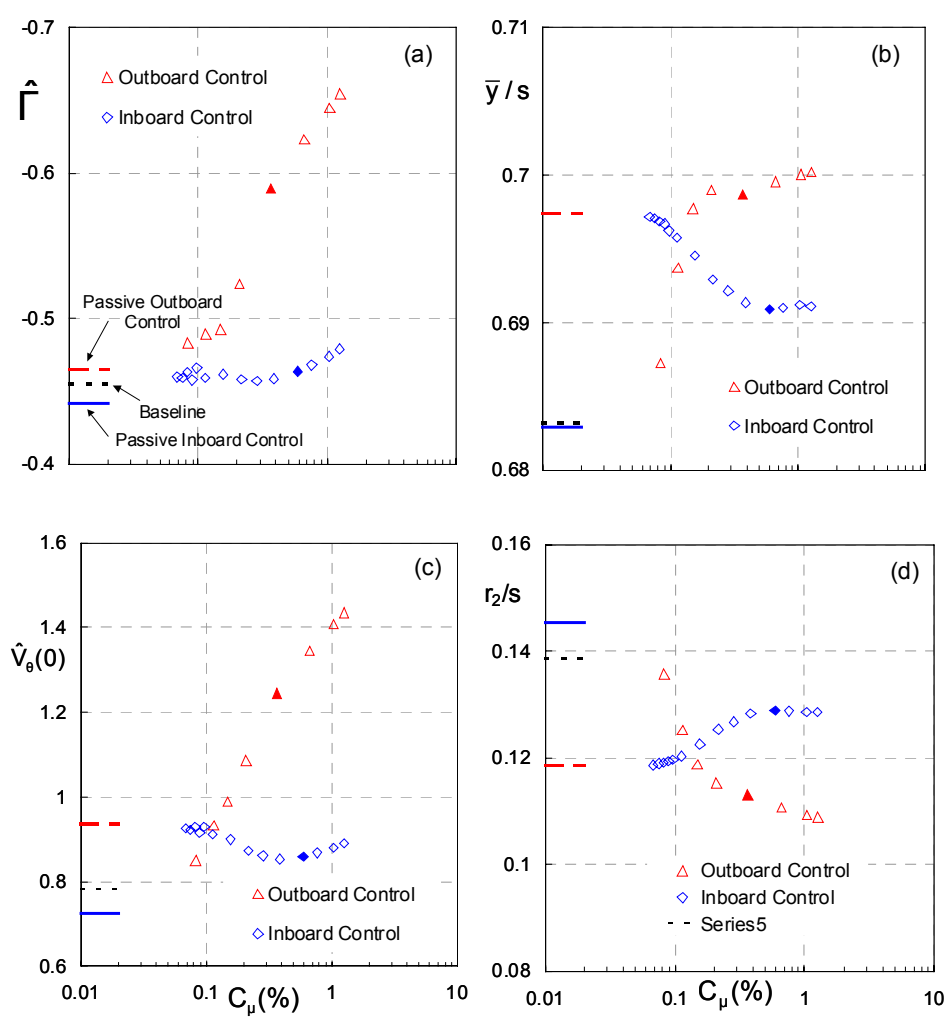

Fig. 15. Vortex characteristics predicted using the DonaldsonBetz rollup relations, corresponding to fig. 12. 

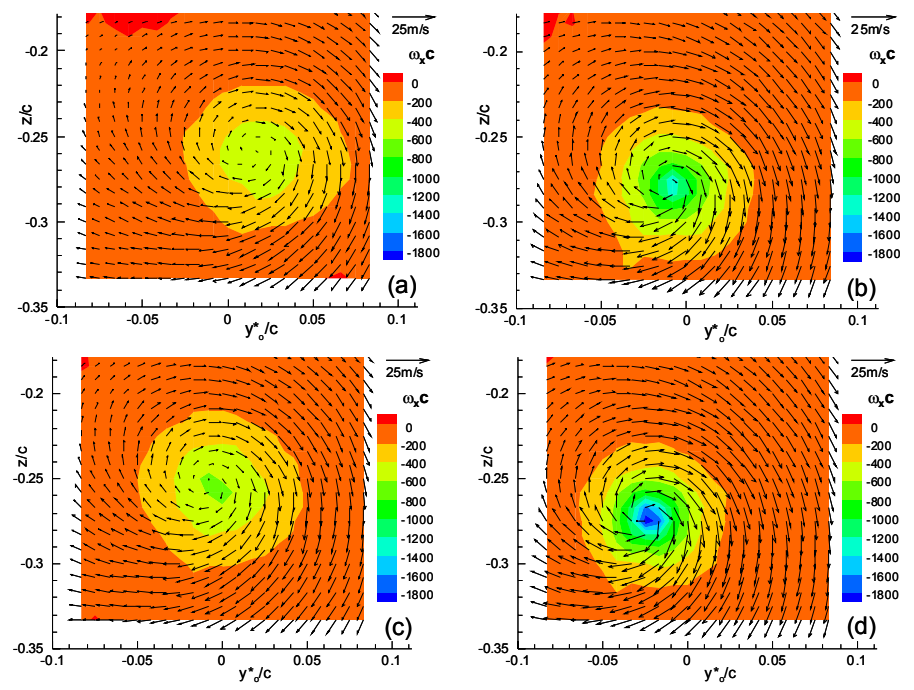

Fig. 16. Seven-hole probe measurements of axial vorticity and in-plane velocity for the scenarios: (a) passive-inboard control; (b) passive outboard control; (c) active-inboard control; (d) active outboard control $(x / c=2)$.
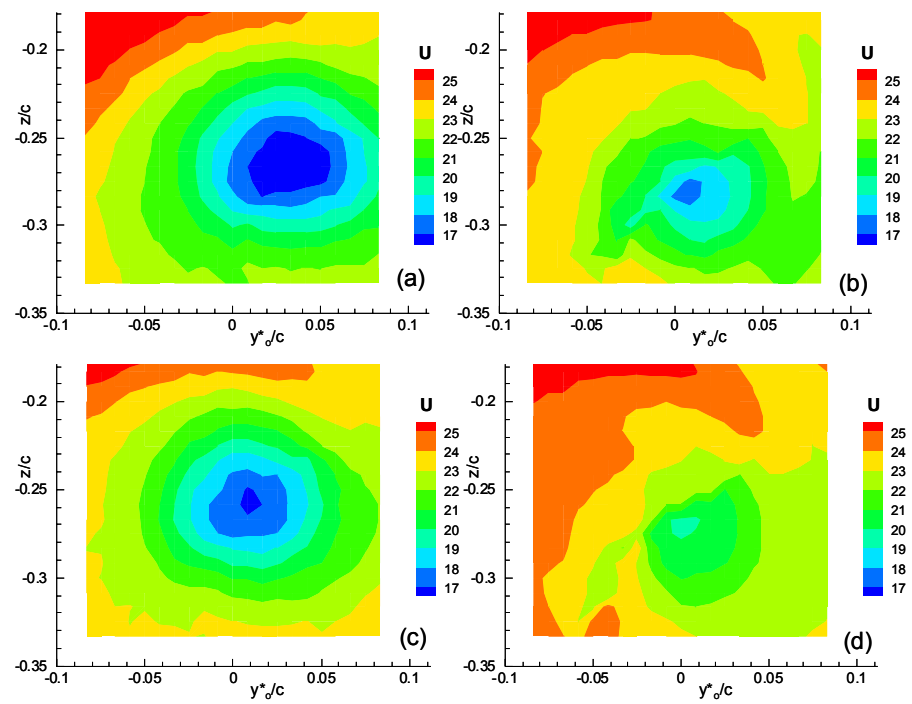

Fig. 17. Seven-hole probe measurements of axial velocity for the scenarios: (a) passive-inboard control; (b) passive outboard control; (c) active-inboard control; (d) active outboard control $(x / c=2)$.

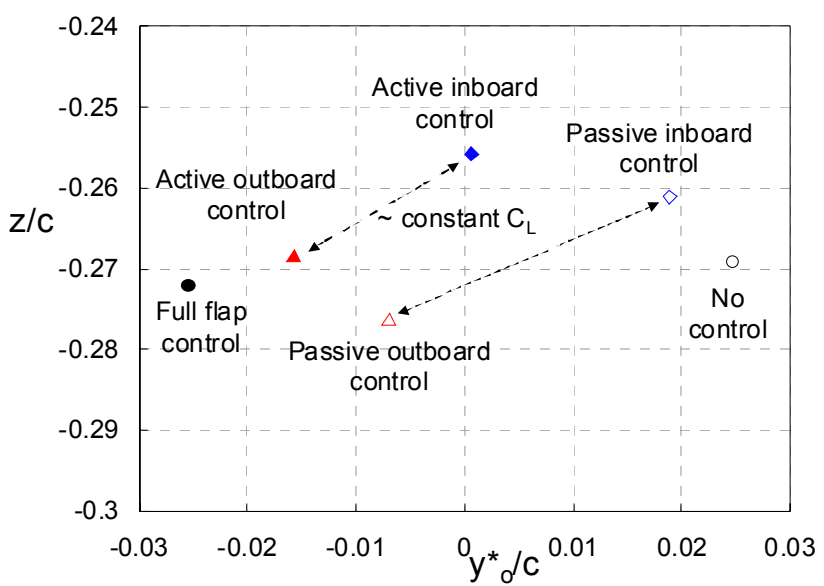

Fig. 18. Vortex map in the $(y, z)$ plane, illustrating the two-dimensional vortex excursion resulting from separation control $(x / c=2)$.

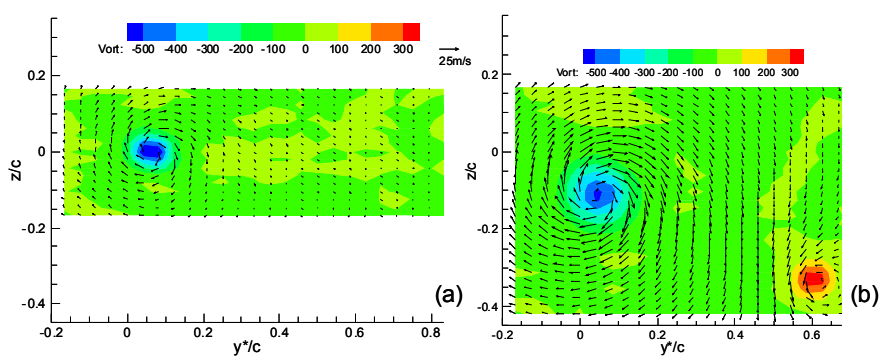

Fig. 19. Vorticity $\left(\omega_{x} c\right)$ and velocity measurements in the wake of the wing tip vortex for (a) the symmetric wing; and (b) with the tip flap deflected $\left(x / c=2 ; \alpha=8^{\circ}\right)$.

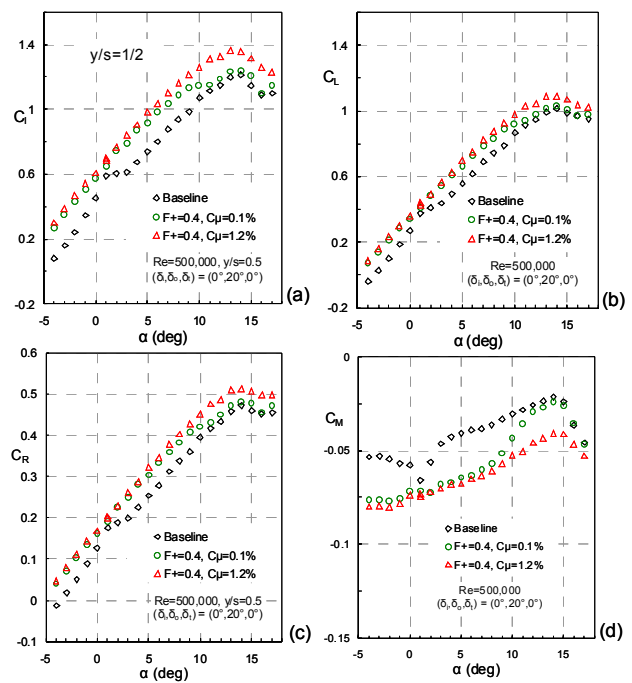

Fig. 20. Aerodynamic coefficients generated with and without separation control on the outboard flap: (a) midspan lift coefficient; (b) wing lift coefficient; (c) rolling moment coefficient; and (d) pitching-moment coefficient. 

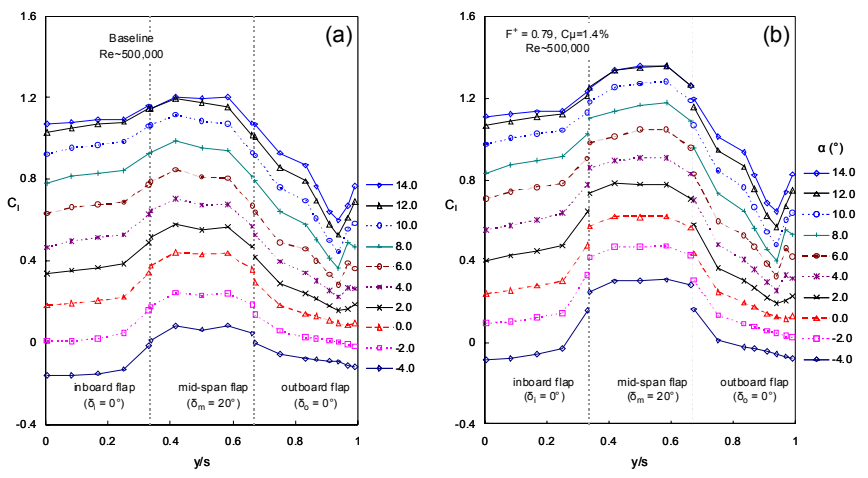

Fig. 21. Span loading generated with and without separation control on the outboard flap (a) baseline; (b) controlled.

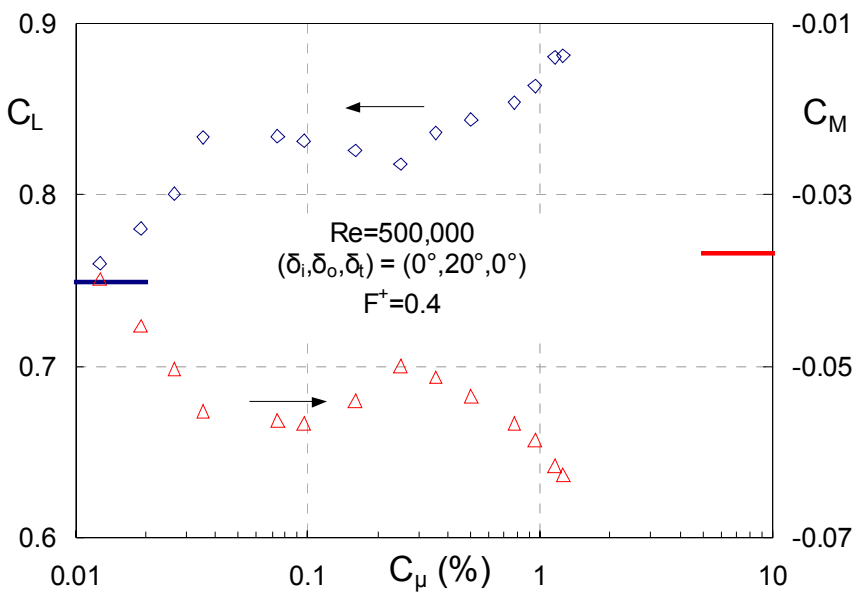

Fig. 22. Effect of increasing midspan separation control amplitude on overall wing lift and moment coefficients.

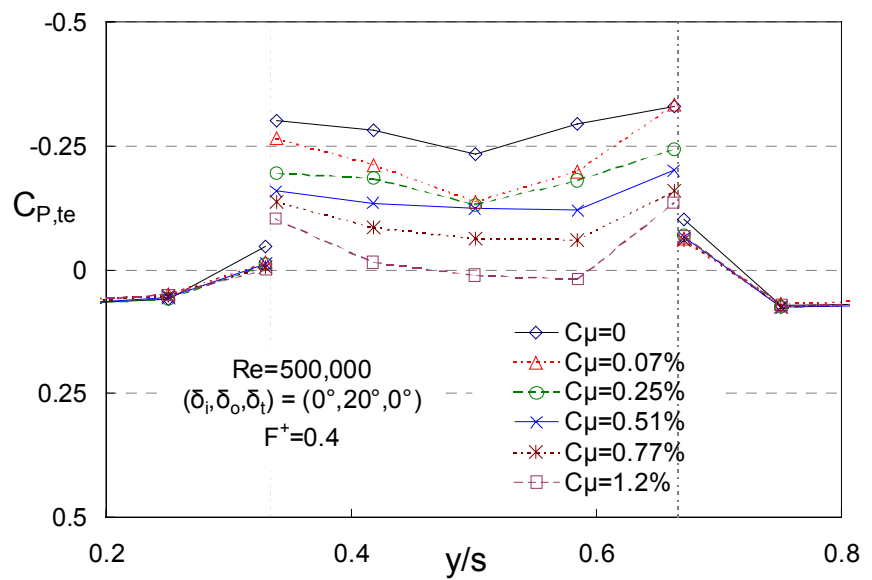

Fig. 23. Spanwise flap trailing-edge pressure recovery for increasing midspan separation control amplitude.
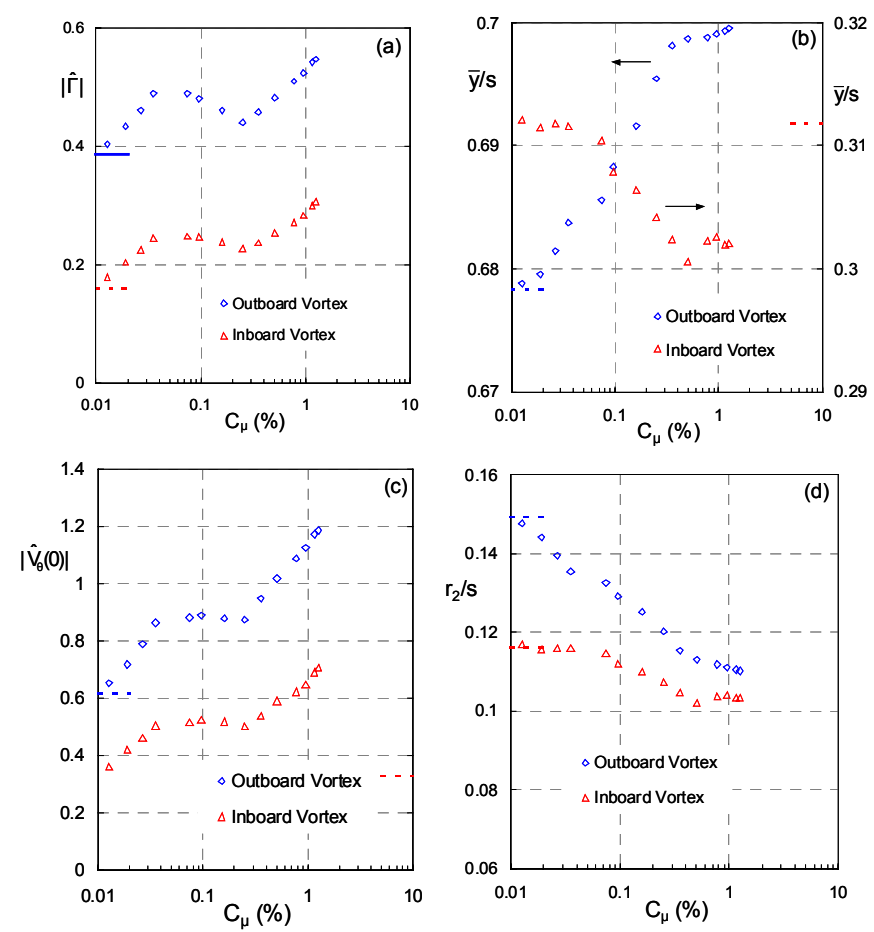

Fig. 24. Donaldson-Betz rollup predictions of vortex characteristics as a function of forcing amplitude corresponding to the data in fig. 22.
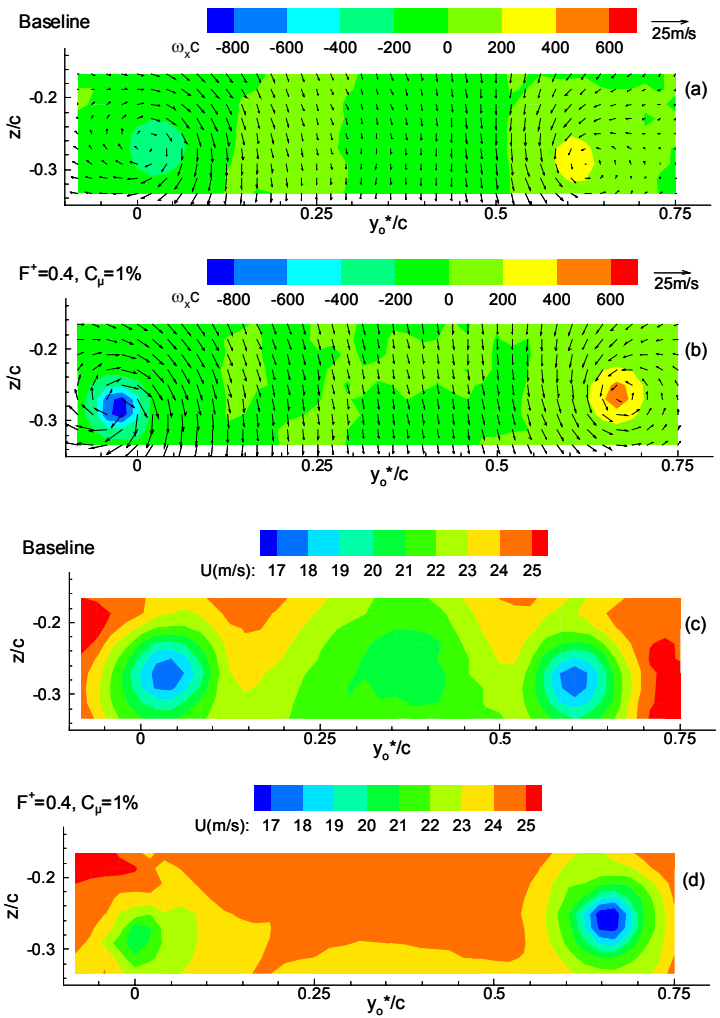

Fig. 25. Seven-hole probe measurements of axial vorticity and velocity for: (a,c) baseline; and (b,d) control cases $(x / c=2)$. 

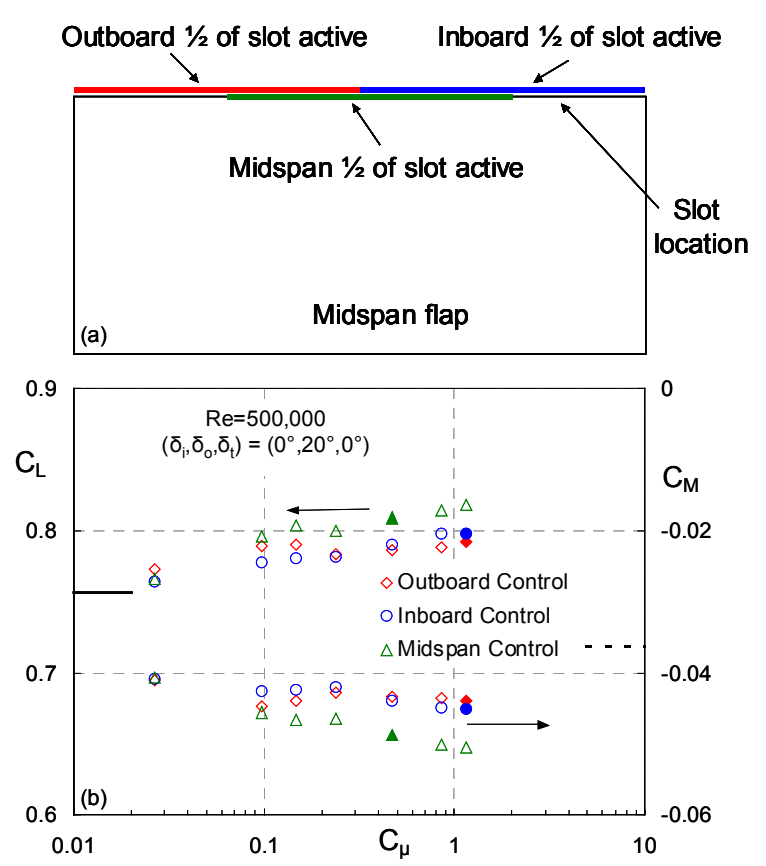

Fig. 26 (a) Schematic illustrating various half-span locations on the outboard slot at which perturbations are introduced; (b) lift and moment coefficients for control introduced from the three locations indicated in fig. 26a.
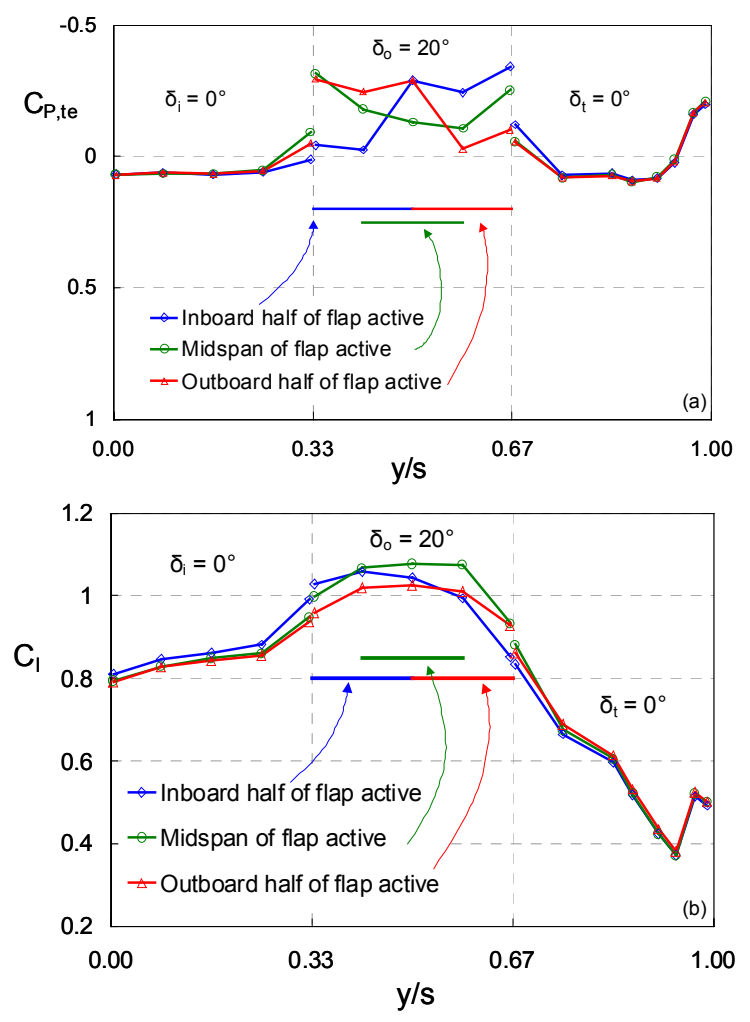

Fig. 27. (a) Trailing-edge pressure recovery and (b) spanloading for control introduced from the three locations indicated in fig. 26a.
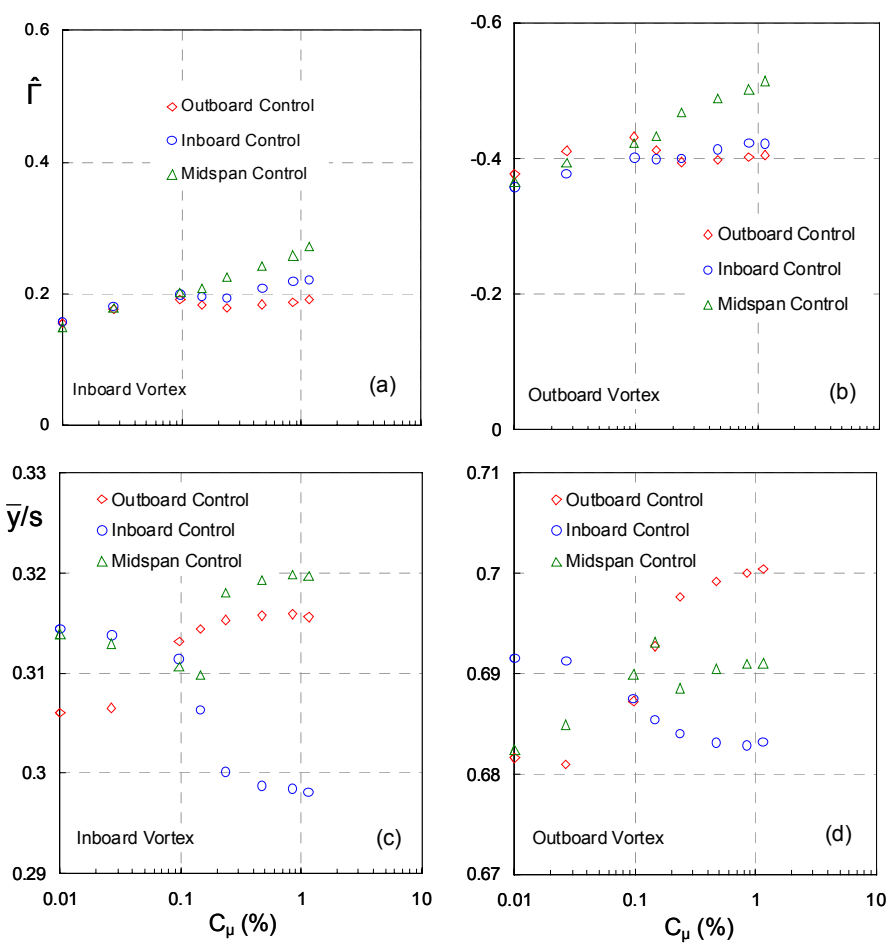

Fig. 28. Donaldson-Betz rollup predictions of vortex characteristics as a function of forcing amplitude at the three locations indicated in fig. 26, for both outboard and inboard vortices.
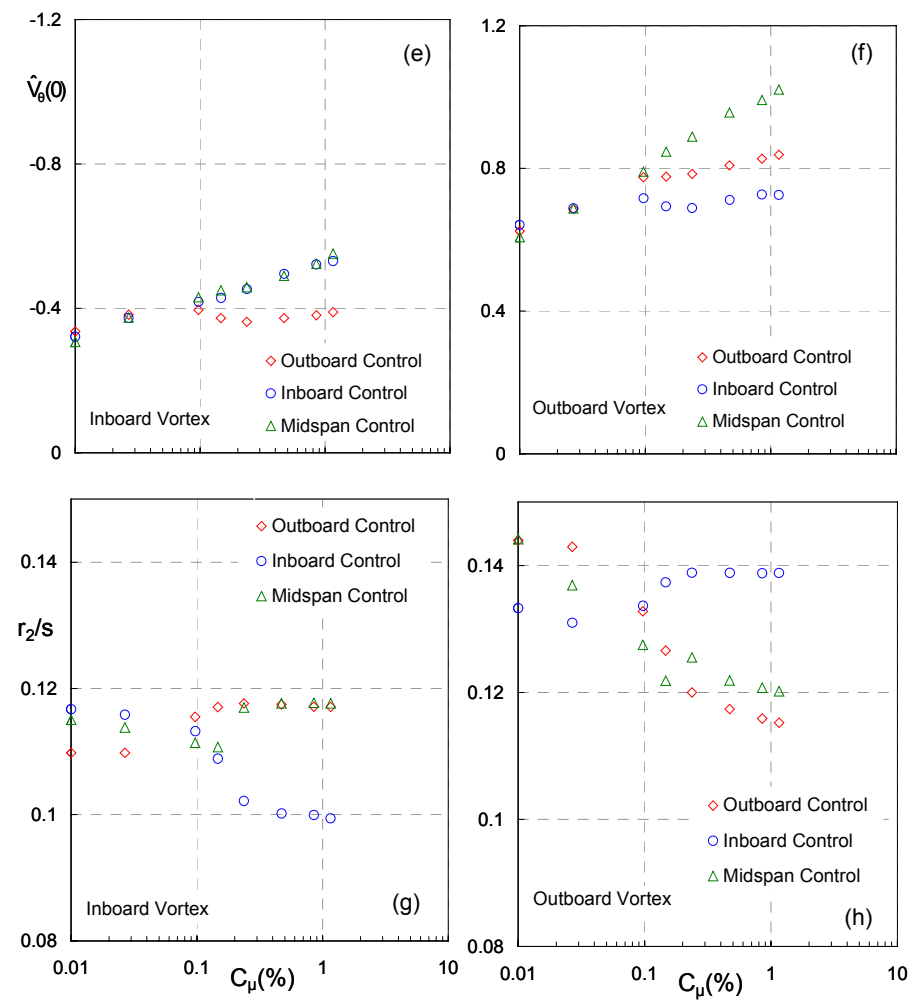

Fig. 28. Contd. 

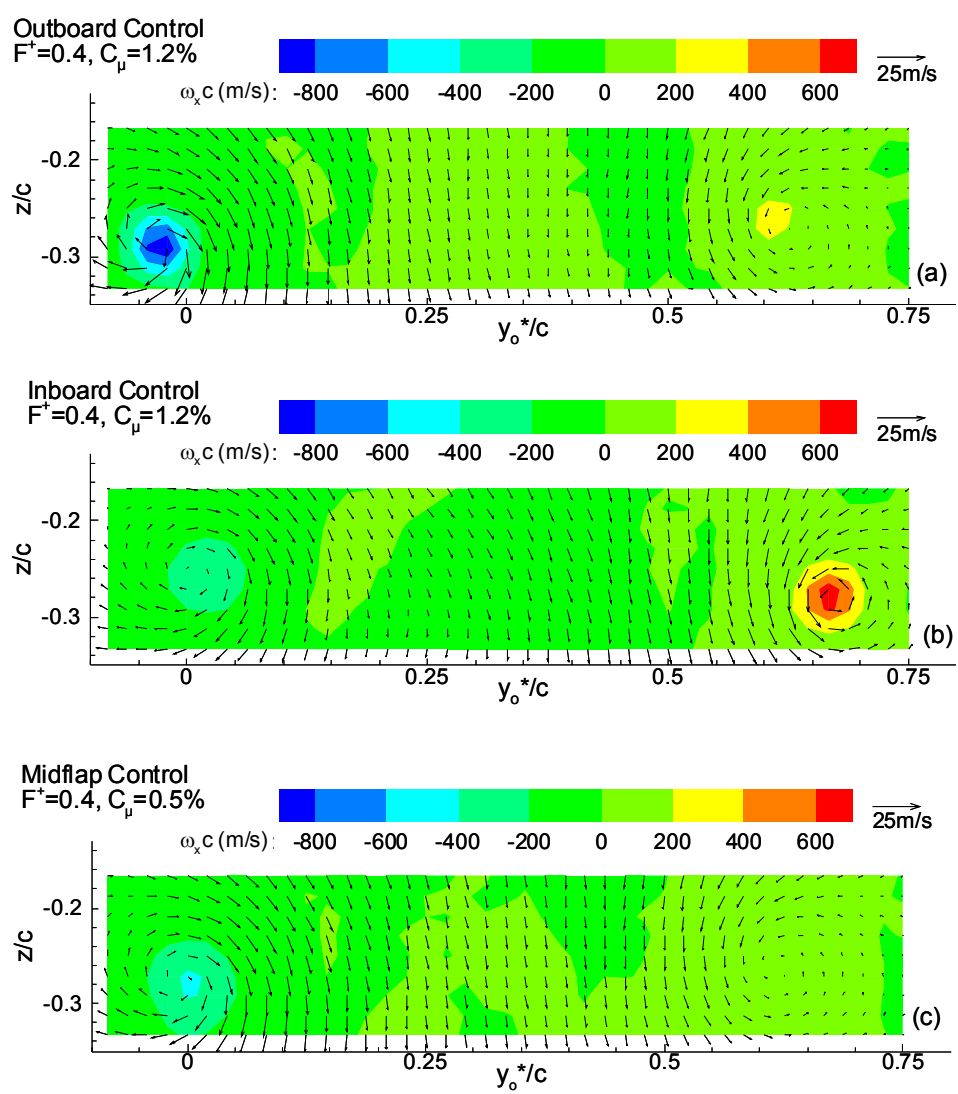

Fig. 29. Seven-hole probe measurements of axial vorticity and inplane velocity for: (a) outboard; (b) inboard; and (c) midspan control cases $(x / c=2)$.

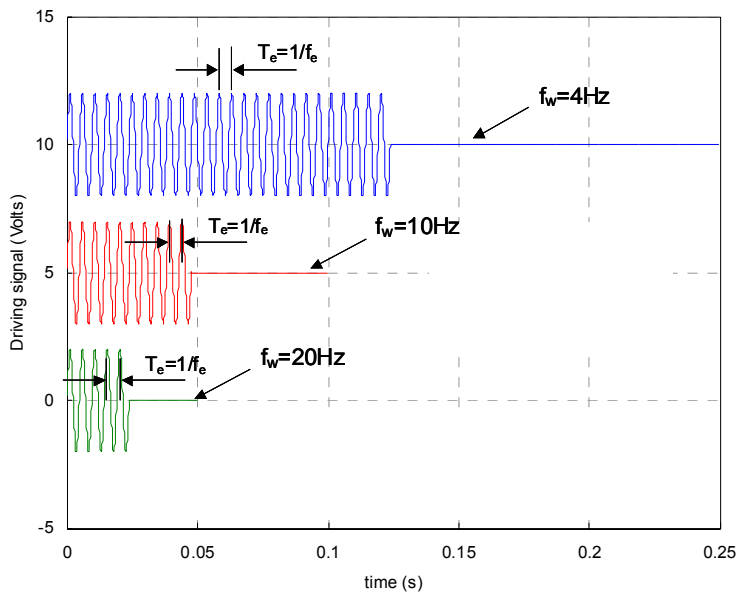

Fig. 30. Function generator signal driven in burst mode at frequency $f_{w}$, and carrier frequency $f_{e}$.
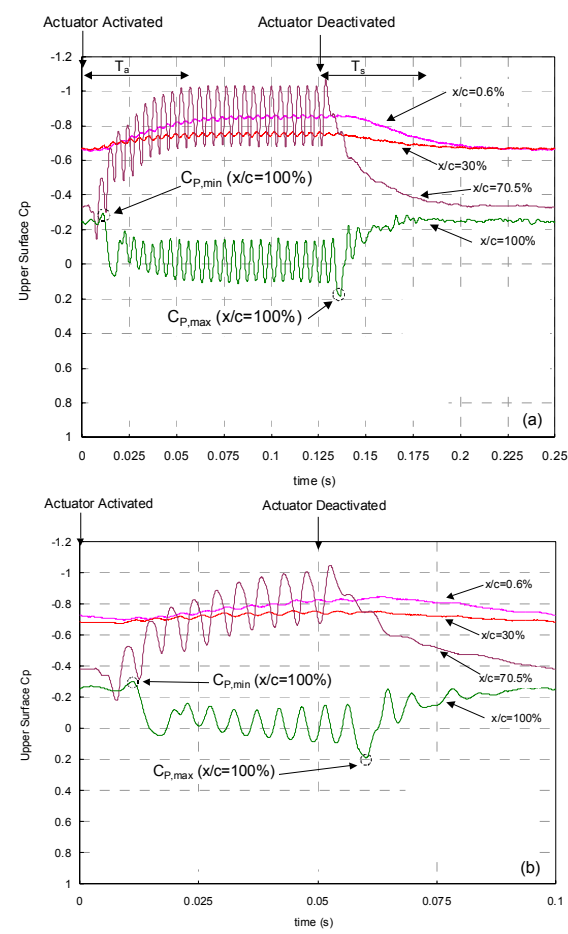

Fig. 31. Upper surface phase-averaged unsteady pressure coefficients at (a) $f_{w}=4 \mathrm{~Hz}$ and (b) $10 \mathrm{~Hz}$ responding dynamically to periodic separation and attachment of the boundary layer.
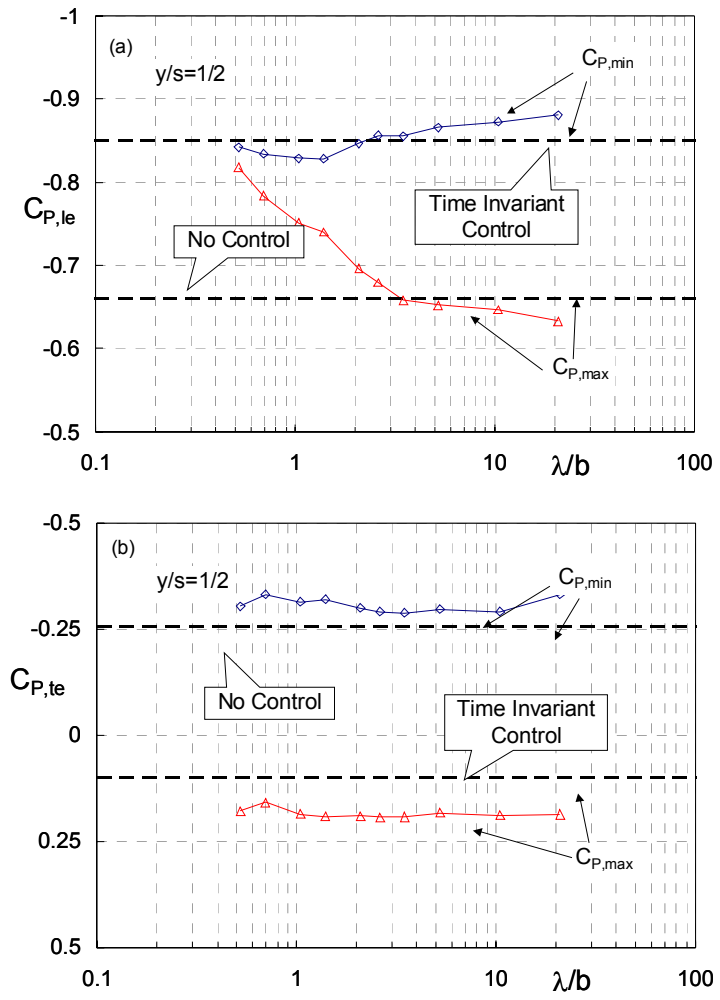

Fig. 32. Maximum and minimum pressure coefficients as a function of wavelength: (a) near the leading-edge and (b) at the trailing-edge. 